\title{
A Triple-Continuum Approach for Modeling Flow and Transport Processes in Fractured Rock
}

\author{
Y. S. Wu, H. H. Liu, G. S. Bodvarsson, and K. E. Zellmer
}

\begin{abstract}
This paper presents a new triple-continuum conceptual model for simulating flow and transport processes in fractured rock. Field data collected from the unsaturated zone of Yucca Mountain, a potential repository site of high-level nuclear waste, show that there are significant numbers of small-scale fractures. Although these small fractures may not contribute to the global flow and transport within the fracture networks, they may have a considerable effect on solute transport and liquid flow between the fractures and the matrix. The effect of these small fractures has not been considered in previous modeling investigations within the context of a continuum approach. A new triple-continuum model (consisting of matrix, small-fracture and large-fracture continua) has been developed to investigate the effect of these small fractures. This paper derives the model formulation and discusses the basic triple-continuum behavior of flow and transport processes under different conditions, using both analytical solutions and numerical approaches. The simulation results from the site-scale model of the unsaturated zone of Yucca Mountain indicate that these small fractures may have an important effect on radionuclide transport within the mountain.
\end{abstract}

Key Words: Naturally fractured reservoir, fractured porous media, double-porosity model, dual-permeability model, triple-continuum model, numerical reservoir simulation, and fractured unsaturated rock. 


\section{Introduction}

The study of flow and transport processes in fractured rock has recently received increased attention because of its importance to underground natural-resource recovery, waste storage, and environmental remediation. Since the 1960s, significant progress has been made towards the understanding and modeling of flow and transport processes in fractured rock (Barenblatt et al., 1960; Warren and Root, 1963; Kazemi, 1969; Pruess and Narasimhan, 1985). Despite these advances, modeling the coupled processes of multiphase fluid flow, heat transfer, and chemical migration in a fractured porous medium remains a conceptual and mathematical challenge. The difficulty stems primarily from (1) the nature of inherent heterogeneity, (2) the uncertainties associated with the characterization of a fracture-matrix system for any field-scale problem, and (3) the difficulties in conceptualizing, understanding, and describing flow and transport processes in such a system.

Mathematical modeling using a continuum approach involves developing conceptual models, incorporating the geometrical information of a given fracture-matrix system, and setting up the general mass and energy conservation equations for overlapping fracturematrix domains. The majority of the computational effort is used to solve the governing equations that couple fluid and heat flow with chemical migration either analytically or numerically. The key issue for simulating flow and transport in fractured rock is how fracture-matrix interactions under different conditions involving multiple processes are handled. The commonly used mathematical methods for dealing with such interactions include: (1) an explicit discrete-fracture and matrix model (e.g., Snow, 1969; Sudicky and McLaren, 1992), (2) the dual-continuum method [including double- and multi-porosity, dual-permeability, or the more general "multiple interacting continua" (MINC) method (e.g., Barenblatt et al., 1960; Warren and Root, 1963; Kazemi, 1969; Pruess and Narasimhan, 1985; Wu and Pruess, 1988)], and (3) the effective-continuum method (ECM) (e.g., Wu, 2000).

The explicit discrete-fracture approach is, in principle, a rigorous model. However, the 
application of this method is computationally intensive. Furthermore, it requires a detailed knowledge of the fracture and matrix geometric properties and their associated spatial distributions (which are rarely known at a given site). This approach becomes more difficult and demanding when modeling multiphase flow and thermal processes. For these reasons, this approach has presently found only limited field application in modeling multiphase, nonisothermal flow and transport processes in fractured rocks.

The dual-continuum method, on the other hand, is conceptually appealing and computationally much less demanding than the discrete-fracture approach. In particular, it is able to handle fracture-matrix interactions more easily than the discrete-fracture model. For these reasons, the dual-continuum approach has currently become the main approach for modeling fluid flow, heat transfer, and chemical transport through fractured reservoirs.

One type of dual-continuum methods, the classical double-porosity model for modeling flow in fractured porous media, was developed in the early 1960s (Barenblatt et al., 1960; Warren and Root, 1963). In this model, a flow domain is composed of matrix blocks with low permeability, embedded in a network of interconnected fractures, and global flow and transport in the formation occurs only through the fracture system conceptualized as an effective continuum. The model treats matrix blocks as spatially distributed sinks or sources to the fracture system without accounting for global matrix-matrix flow. However, the model does account for fracture-matrix interflow, based on a quasi-steadystate assumption.

In an attempt to incorporate additional matrix-matrix interactions, the dual-permeability model has been developed. This type of dual-continuum model considers global flow occurring not only between fractures but also between matrix gridblocks. In this approach, the fractures and the matrix are each represented by separate gridblocks that are connected to each other. The same quasi-steady state flow assumption as that in the double-porosity concept is used to handled fracture-matrix interflow. 
As a generalization to the double-porosity model, a more rigorous dual-continuum method, the MINC concept (Pruess and Narasimhan, 1985), describes gradients of pressures, temperatures, and concentrations between fractures and matrix by further subdividing individual matrix blocks. This approach provides a better approximation for transient fracture-matrix interactions than the quasi-steady state flow assumption used by Warren and Root (1963) for the double-porosity or dual-permeability model. Fluid and heat flow and transport from the fractures into the matrix blocks can be modeled by means of one- or multidimensional strings of nested gridblocks.

As an alternative method, the ECM represents fractures and rock matrix as a single effective continuum. ECM models have long been used for modeling fracture-matrix flow because of their simplicity in data requirements and their computational efficiency. This approach may be applicable to modeling multiphase, nonisothermal flow and solute transport in fractured porous media under thermodynamic equilibrium conditions $(\mathrm{Wu}$, 2000). When rapid flow and transport processes occur in many subsurface fractured reservoirs, however, thermodynamic equilibrium conditions can not (in general) be satisfied.

Investigations concerning the feasibility of using the unsaturated zone (UZ) of Yucca Mountain as a repository for high-level nuclear waste have generated considerable research interest in understanding and modeling flow and transport processes in unsaturated fractured rock. The unsaturated zone of Yucca Mountain, with a thickness between 500 and $700 \mathrm{~m}$, has been studied extensively for the past few decades. Many types of data have been collected at the site and used to assist in the characterization of the UZ system.

Since the 1980s, a number of numerical models have been developed specifically for evaluating UZ hydrologic conditions at Yucca Mountain. Studies before the 1990s primarily used one- and two-dimensional models to understand basic flow and transport 
processes in fractured rock (Rulon et al., 1986; Pollock, 1986; Tsang and Pruess, 1987). In the early 1990s, Wittwer et al. (1995) began development of a three-dimensional (3-D) model that used an ECM approach and incorporated many geological and hydrological complexities (e.g., geological layering, degree of welding, fault offsets, different matrix and fracture properties). Ahlers et al. (1995) continued this work by increasing the numerical and spatial resolution of the 3-D ECM UZ model. Their studies considered processes such as gas pressures and moisture flow, temperature and heat flow analyses, and rock-property evaluation through inverse modeling. Since then, more comprehensive mountain-scale numerical models (e.g., Wu et al., 1998; 1999) have been developed to study flow processes in the UZ of Yucca Mountain, using the more rigorous dualpermeability concept. A comparative study of the different approaches for handling fracture-matrix interactions was conducted as an effort to investigate the rapid movement of solute in fractured tuffs at Yucca Mountain (McLaren et al., 2000).

Although many conceptual models for fracture-matrix interaction have been evaluated for Yucca Mountain site-characterization studies (Doughty, 1999), the most widely used model is currently based on the dual-permeability concept. It was chosen for use in sitecharacterization in part because it has proved to be capable of matching many types of field observed data (e.g., Wu et al., 1998; 1999). Another consideration is that net infiltration rates at the site are estimated to be very low (on the order of millimeters/year), or close to saturated matrix hydraulic conductivity. Then global flow through matrix cannot be ignored anymore. However, recent field studies and tests, in particular, fracture mapping data (Liu et al., 2000), collected along the walls of the underground tunnels reveal that there exists a significantly large variety in fracture sizes from center meters to tens of meters. There is a considerable amount of small-scale fractures that has not been considered in the previous modeling studies. Although the majority of these small fractures may not contribute much to global flow and transport through the UZ system, they may provide large amounts of storage pore space and allow for additional connection areas for well-connected, large-scale fractures and surrounding matrix blocks, which ultimately affect fracture-matrix interactions. On the other hand, the currently used dual- 
permeability model is unable to include the effects that a large number of small fractures may have on the system.

To overcome the limitations of the dual-continuum approach, we have developed a triplecontinuum conceptual model to investigate the impact that small-scale fractures have on flow and transport processes in fractured rocks. This new conceptual model subdivides fractures into two types: large-scale and small-scale. Large-scale fractures are those responsible for global connections; small-scale fractures are those that provide largefracture storage space and enhance the local connections to the matrix system without contributing to global flow or transport. Because the triple-continuum model is composed of the rock matrix and two types of fractures, it can be regarded as an extension of the dual-permeability model. The new model has been implemented into the TOUGH2 code (Pruess, 1991).

In this paper, we investigate the triple-continuum behavior of flow and transport processes in fractured rocks based on numerical modeling results and on an analytical solution. We discuss issues related to the determination of small-fracture properties using observations from single-phase flow processes. As application examples, we demonstrate how to apply the proposed triple-continuum model to field problems at Yucca Mountain in (1) estimating model-related fracture-matrix parameters using field observation data and an inverse-modeling approach; (2) simulation of 3-D site-scale flow and transport; and (3) performing 2-D cross-sectional investigations of flow, transport, and heat transfer.

\section{Conceptual Model and Mathematical Formulation}

Following the pioneering work by Barenblatt et al. (1960) and Warren and Root (1963), several triple-porosity models have been proposed in the literature (e.g., Closmann, 1975, Wu and Ge, 1983; Abdassah and Ershaghis, 1986; Bai et al., 1993) for describing flow through fractured rocks. Liu et al. (2001) has recently presented a new triple-porosity model for flow in a fracture-matrix system including cavities within the lithophysal rock matrix (as an additional porous portion of matrix) at Yucca Mountain. In general, these 
developed models were focused on heterogeneity of rock matrix, i.e., subdividing rock matrix into two or more subdomains with different porous medium properties.

According to observation data at Yucca Mountain, there are many more "small" fractures than "large" fractures in the UZ (Liu et al., 2000). In an attempt to incorporate various scale fracture into our triple-continuum model, we conceptualize the fracture-matrix system as consisting of a single porous-medium rock matrix and two types of fractures: (1) "large" globally connected fractures and (2) "small" fractures that are locally connected to the large fractures and the rock matrix. Figure 1 illustrates the triplecontinuum concept, as compared with ECM, double-porosity, and dual-permeability models. The triple-continuum method (Figure 1d) extends the dual-permeability concept by adding one more connection (via small fractures) between the large fractures and the matrix blocks. Note that small fractures that are not directly connected with large fractures (i.e., fractures that are isolated within the matrix) are not considered to be part of the small fracture continuum in this model. Instead, these fractures are considered to be part of the matrix continuum.

Figure 2 illustrates the triple-continuum conceptualization for a fracture-matrix system in which the small-fracture/matrix connections occur in only one dimension (shown horizontally). A second set of small-fracture/matrix connections can also be added to occur in two dimensions (i.e., horizontally and vertically, Figure 3). In a similar manner, a third set of fractures can be added to extend the system of small-fracture/matrix interctions to occur in three dimensions. In all cases, large fractures are represented as major through-going parallel plates, while small fractures are treated as minor plates that are perpendicular to large fractures and uniformly distributed along the large fractures. The triple-continuum model is not limited to the orthogonal idealization of the fracture systems presented in Figures 2 and 3, however. Irregular and stochastic distributions of small and large fractures can be handled using a similar approach to the MINC methodology (Pruess, 1983) as long as the actual distribution patterns are known. 
In principle, the proposed triple-continuum model, like the dual-continuum approach, uses an "effective" porous medium to approximate the two types of fractures and the rock matrix, and considers the three separate continua to be spatially. The triple-continuum model relies on the one critical assumption that approximate thermodynamic equilibrium exists (locally) within each of the three continua at all times at a given location. Based on the local equilibrium assumption, thermodynamic variables, such pressures, concentrations and temperatures, can be defined for each continuum. Therefore, multiphase fluid flow, multicomponent transport, and heat-transfer processes can be described using a continuum approach in the two types of fractures and the matrix, respectively, using the representative elementary volume (REV) concept for each continuum of the formation.

In the triple-continuum approach, processes of flow and transport in fractured rocks are described separately, using a triplet of governing equations for the two fracture and matrix continua. This conceptualization results in a set of partial differential equations for flow and transport in each continuum, which are in the same form as that for a single porous medium. Let us consider a two-phase (liquid and gas), nonisothermal system. The corresponding transport equation of each component $\kappa$ in the two-phase system within each of three continua can be written as follows:

$$
\begin{aligned}
& \frac{\partial}{\partial \mathrm{t}}\left\{\phi \sum_{\beta}\left(\rho_{\beta} \mathrm{S}_{\beta} \mathrm{X}_{\beta}^{\mathrm{k}}\right)+(1-\phi) \rho_{\mathrm{s}} \rho_{\mathrm{L}} \mathrm{X}_{\mathrm{L}}^{\mathrm{k}} \mathrm{K}_{\mathrm{d}}^{\mathrm{k}}\right\}+\lambda_{\mathrm{\kappa}}\left\{\phi \sum_{\beta}\left(\rho_{\beta} \mathrm{S}_{\beta} \mathrm{X}_{\beta}^{\mathrm{k}}\right)+(1-\phi) \rho_{\mathrm{s}} \rho_{\mathrm{L}} \mathrm{X}_{\mathrm{L}}^{\mathrm{k}} \mathrm{K}_{\mathrm{d}}^{\mathrm{k}}\right\} \\
& =-\sum_{\beta} \nabla \cdot\left(\rho_{\beta} \mathrm{X}_{\beta}^{\mathrm{k}} \mathbf{v}_{\beta}\right)+\sum_{\beta} \nabla \cdot\left(\rho_{\beta} \underline{D}_{\beta}^{\mathrm{k}} \bullet \nabla \mathrm{X}_{\beta}^{\mathrm{k}}\right)+\mathrm{q}^{\mathrm{k}}
\end{aligned}
$$

and the energy conservation equation is:

$$
\begin{aligned}
& \frac{\partial}{\partial \mathrm{t}}\left\{\sum_{\beta}\left(\phi \rho_{\beta} \mathrm{S}_{\beta} \mathrm{U}_{\beta}\right)+(1-\phi) \rho_{\mathrm{s}} \mathrm{U}_{\mathrm{s}}\right\}=-\sum_{\beta} \nabla \bullet\left(\mathrm{h}_{\beta} \rho_{\beta} \mathbf{v}_{\beta}\right) \\
& +\sum_{\beta} \sum_{\mathrm{K}} \nabla \bullet\left(\rho_{\beta} \mathrm{h}_{\beta}^{\mathrm{K}} \underline{D}_{\beta}^{\mathrm{K}} \bullet \nabla \mathrm{X}_{\beta}^{\mathrm{K}}\right)+\nabla \bullet\left(\mathrm{K}_{\mathrm{th}} \nabla \mathrm{T}\right)+\mathrm{q}^{\mathrm{E}}
\end{aligned}
$$


where subscript $\beta$ is an index for fluid phase ( $\beta=\mathrm{L}$ for liquid and $\mathrm{g}$ for gas); $\kappa$ is an index for components; other symbols and notations are defined in the Table of Nomenclature (included at the end of the text). In general, Equations (1) and (2) can be used to describe flow and transport processes within each of the three continua. When applied, however, they are much simplified for small fracture and matrix continua and their coupling is treated using physically based approaches, as discussed in Sections 3 numerically and 4 analytically.

\section{Numerical Implementation}

The numerical implementation of the triple-continuum model discussed above is based on the framework of the TOUGH2 code (Pruess, 1991; Wu and Pruess, 2000). The component mass- and energy-conservation equations (Equations 1 and 2, respectively) are discretized in space using an integral finite-difference method. The time discretization is carried out with a backward, first-order, finite-difference scheme. The discrete nonlinear equations for water, air, tracer/radionuclide, and heat at a gridblock $\mathrm{n}$ can be written as follows:

$$
\begin{gathered}
R_{n}^{\kappa, k+1}=M_{n}^{\kappa, k+1}\left(1+\lambda_{\kappa} \Delta t\right)-M_{n}^{\kappa, k}-\frac{\Delta t}{V_{n}}\left\{\sum_{m}\left(A_{n m} F_{n m}^{(\kappa), k+1}\right)+V_{n} q_{n}^{\kappa, k+1}\right\} \\
(\kappa=1,2,3, \text { and } 4)
\end{gathered}
$$

where the superscript $\kappa$ is an equation or component index, and $\kappa=1,2,3$, and 4 denote water, air, tracer/radionuclide and heat, respectively. The decay constants, $\lambda_{\kappa}$, are zero unless $\kappa=3$ for a decaying tracer/radionuclide component. The summation in (3) accounts for mass or energy inflow/outflow contributed within the continuum and/or other continua.

Wu and Pruess (2000) provide detailed formulation for the evaluation of accumulation $\left(M_{n}\right)$ and flow $\left(F_{n, m}\right)$ terms for Equation (3), including how to calculate dispersive (conductive for heat) and advective mass and heat fluxes, respectively. In addition, we use the MINC techniques directly (Pruess, 1983) for handling flow and interactions between large fractures and the matrix. However, this work introduces small fractures as an additional continuum. To evaluate the flow terms associated with the interactions of 
the small fractures with the large fractures or the small fractures with the matrix, we require additional geometric parameters such as the interface areas and characteristic lengths for these connections. In this study, small fractures are represented by one cell locally interacting with large fracture and matrix systems (Figure 1).

Table 1 summarizes the parameters of the equations needed in order to determine the characteristic distances used in calculating flow between three continua for the cases of regular one-, two- and three-dimensional large fracture networks, each with uniform distributions of small fractures. The quasi-steady state flow assumption of Warren and Root (1963) is used to derive the characteristic parameters, listed in Table 1. The flow distance between small fractures (f) and large fractures (F) is taken to be half of the characteristic length of the small fractures within a matrix block (Figures 2 and 3). Furthermore, the interface areas between the small fractures and the matrix (M) are calculated using the geometric data of the small fractures. Areas between the large fractures and the matrix and between the large fractures and the small fractures are treated using the geometry of the large fractures. This treatment has implicitly defined the permeabilities of the two fractures in a continuum sense such that bulk connection areas are needed in calculating Darcy flow between the two fracture continua. In summary, we extend the Warren and Root approach to evaluate interactions along F-M and f-M connections.

Table 1. Characteristic distances* for evaluating flow terms between two fracture and matrix systems.

\begin{tabular}{|c|c|l|l|l|l|l|}
\hline $\begin{array}{c}\text { Large- } \\
\text { Fracture } \\
\text { Networks }\end{array}$ & $\begin{array}{c}\text { Dimensions } \\
\text { of Matrix } \\
\text { Blocks }\end{array}$ & $\begin{array}{l}\text { Characteristic } \\
\text { Dimension (m) of } \\
\text { Large Fractures }\end{array}$ & $\begin{array}{l}\text { Characteristic } \\
\text { F-M Distances } \\
(\mathrm{m})\end{array}$ & $\begin{array}{l}\text { Characteristic } \\
\text { Dimension (m) } \\
\text { of Small } \\
\text { Fractures }\end{array}$ & $\begin{array}{l}\text { Characteristic } \\
\text { F-f Distances } \\
(\mathrm{m})\end{array}$ & $\begin{array}{l}\text { Characteristic } \\
\text { f-M Distances } \\
(\mathrm{m})\end{array}$ \\
\hline 1-D & $\mathrm{A}$ & $l_{F}=\mathrm{A}$ & $l_{F M}=l_{F} / 6$ & $l_{f}=\mathrm{a}$ & $l_{F f}=l_{x} / 2$ & $l_{f M}=l_{f} / 6$ \\
\hline 2-D & $\mathrm{A}$ & $l_{F}=\frac{2 \mathrm{AB}}{\mathrm{A}+\mathrm{B}}$ & $l_{F M}=l_{F} / 8$ & $l_{f}=\frac{2 \mathrm{ab}}{\mathrm{a}+\mathrm{b}}$ & $l_{F f}=\frac{l_{x}+l_{y}}{2}$ & $l_{f M}=l_{f} / 8$ \\
\hline
\end{tabular}




\begin{tabular}{|c|l|l|l|l|l|l|}
\hline $3-\mathrm{D}$ & $\mathrm{A}$ & & & & \\
& $\mathrm{B}$ & $l_{F}=\frac{3 \mathrm{ABC}}{\mathrm{A}+\mathrm{B}+\mathrm{C}}$ & $l_{F M}=l_{F} / 10$ & $l_{f}=\frac{3 \mathrm{abc}}{\mathrm{a}+\mathrm{b}+\mathrm{c}}$ & & $l_{x}+l_{y}+l_{z}$ \\
& $\mathrm{C}$ & & $l_{f M}=l_{f} / 10$ \\
\hline
\end{tabular}

* Note in Table 1, A, B and C are dimensions of matrix blocks along $\mathrm{x}, \mathrm{y}$ and $\mathrm{z}$ directions, respectively; $\mathrm{a}, \mathrm{b}$ and $\mathrm{c}$ are fracture-spacings of small fractures along $\mathrm{x}, \mathrm{y}$ and $\mathrm{z}$ directions, respectively; subscript $\mathrm{F}$ represents large-fracture, f small-fracture and M matrix systems, respectively.

The model formulation (Section 2) is applicable to both single-continuum and multicontinuum conditions. When handling flow and transport through triple-continuum fractured rock, one of the main challenges is generating a mesh that represents both types of fractures as well as the matrix continua. This triple-continuum, fracture-matrix mesh should be generated based on the MINC approach (Pruess, 1983), i.e., starting from a primary or single-porous medium mesh, which uses buck volume of formation and layering only. Then geometric information of the corresponding two-type fractures within one formation subdomain or one finite-difference gridblock of the primary mesh is used, fractures will be lumped into the large fracture continuum and the small fracture continuum, respectively. The rest is regarded as the matrix continuum. The connection distances and interface areas are calculated accordingly, using the correlations listed in Table 1 and the geometric data of the fractures. Once a proper mesh for a triplecontinuum system is generated, fracture and matrix blocks are specified to represent fracture or matrix continua, separately. They are treated in exactly the same way mathematically during the solution in the TOUGH2 code.

\section{Triple-Continuum Behavior of Flow and Transport Processes under Single- Phase Flow Conditions}

In this section, we discuss flow and transport behavior through the triple-continuum model under single-phase conditions (air flow in dry fractures or water flow in saturated fractured rocks). Both analytical and numerical approaches are used in this section. Note that this discussion builds on Warran and Root (1963) and Wu and Ge (1983). 


\subsection{Analytical Solution}

In order to use an analytical approach, we have to further simplify Equations (1) and (2) to a case involving slightly compressible, isothermal flow. We also assume that global flow through the matrix system is insignificant. Furthermore, the quasi steady-state flow assumption is used for flow between both a large-fracture continuum and the matrix, and a small-fracture continuum and the matrix. Given these assumptions, flow in a triplecontinuum system can be described as follows:

For flow through large fractures:

$$
-\nabla \cdot(\rho \mathbf{v})-\phi_{M} C_{M} \frac{\partial P_{M}}{\partial t}-\phi_{f} C_{f} \frac{\partial P_{f}}{\partial t}=\phi_{F} C_{F} \rho_{i} \frac{\partial P_{F}}{\partial t}
$$

For interacting with small fractures:

$$
\phi_{\mathrm{f}} \mathrm{C}_{\mathrm{f}} \frac{\partial \mathrm{P}_{\mathrm{f}}}{\partial \mathrm{t}}=\frac{\alpha_{\mathrm{Ff}} \mathrm{k}_{\mathrm{f}}}{\mu}\left(\mathrm{P}_{\mathrm{F}}-\mathrm{P}_{\mathrm{f}}\right)+\frac{\alpha_{\mathrm{fM}} \mathrm{k}_{\mathrm{M}}}{\mu}\left(\mathrm{P}_{\mathrm{M}}-\mathrm{P}_{\mathrm{f}}\right)
$$

For interacting with matrix:

$$
\phi_{M} C_{M} \frac{\partial \mathrm{P}_{M}}{\partial \mathrm{t}}=\frac{\alpha_{\mathrm{FM}} \mathrm{k}_{\mathrm{M}}}{\mu}\left(\mathrm{P}_{\mathrm{F}}-\mathrm{P}_{\mathrm{M}}\right)+\frac{\alpha_{\mathrm{fM}} \mathrm{k}_{\mathrm{M}}}{\mu}\left(\mathrm{P}_{\mathrm{f}}-\mathrm{P}_{\mathrm{M}}\right)
$$

where the shape factor for F-M or f-M is defined by Warren and Root (1963)

$$
\alpha_{\mathrm{FM}}=\alpha_{\mathrm{fM}}=\alpha
$$

For F-f interaction, the shape factor for one-dimensional small fractures is defined as

$$
\alpha_{\mathrm{Ff}}=\frac{\mathrm{A}_{\mathrm{Ff}}}{l_{F f}}
$$

in which $\mathrm{A}_{\mathrm{Ff}}$ is the total large-fracture and small-fracture connection area per unit volume of $\operatorname{rock}\left(\mathrm{m}^{2} / \mathrm{m}^{3}\right)$.

The problem under consideration is one-dimensional radial flow into (or out of) a fully penetrating well in a radially infinite, horizontal reservoir that contains uniform fracture and matrix properties. The system is subject to uniform initial pressure and a constant injection rate at the well. When wellbore storage and skin effects can be ignored, an asymptotic solution for a dimensionless pressure can be derived in terms of dimensionless 
variables (Liu et al., 2001):

$\mathrm{p}_{\mathrm{D}}\left(\mathrm{r}_{\mathrm{D}}=1, \mathrm{t}_{\mathrm{D}}\right)=\frac{1}{2}\left[\ln \mathrm{t}_{\mathrm{D}}+0.80909+\mathrm{E}_{\mathrm{i}}\left(-\mathrm{A}_{1} \mathrm{t}_{\mathrm{D}}\right)-\mathrm{E}_{\mathrm{i}}\left(-\mathrm{B}_{1} \mathrm{t}_{\mathrm{D}}\right)+\mathrm{E}_{\mathrm{i}}\left(-\mathrm{A}_{2} \mathrm{t}_{\mathrm{D}}\right)-\mathrm{E}_{\mathrm{i}}\left(-\mathrm{B}_{2} \mathrm{t}_{\mathrm{D}}\right)\right]$

where the function $\mathrm{E}_{\mathrm{i}}$ is called the exponential integral. Variables $\mathrm{A}_{1}, \mathrm{~A}_{2}, \mathrm{~B}_{1}$, and $\mathrm{B}_{2}$, and other dimensionless variables used are defined in Table 2:

Table 2. Dimensionless Parameters and Variables Used in the Analytical Solutions of Flow through a Triple-Continuum Reservoir.

\begin{tabular}{|c|c|}
\hline Parameter & Definition \\
\hline Dimensionless time & $\mathrm{t}_{\mathrm{D}}=\frac{\mathrm{k}_{\mathrm{F}} \mathrm{t}}{\mu \mathrm{r}_{\mathrm{w}}^{2}\left(\phi_{\mathrm{m}} \mathrm{C}_{\mathrm{m}}+\phi_{\mathrm{f}} \mathrm{C}_{\mathrm{f}}+\phi_{\mathrm{F}} \mathrm{C}_{\mathrm{F}}\right)}$ \\
\hline Dimensionless radius & $r_{D}=\frac{r}{r_{w}}$ \\
\hline Dimensionless pressure & $\mathrm{P}_{\mathrm{D}}=\frac{\left.\mathrm{P}_{\mathrm{i}}-\mathrm{P}_{\mathrm{F}}(\mathrm{r}, \mathrm{t})\right)}{\frac{\mathrm{q} \mu}{2 \pi \mathrm{k}_{\mathrm{F}} \mathrm{h}}}$ \\
\hline F-M interporosity parameter & $\lambda_{\mathrm{FM}}=\frac{\alpha_{\mathrm{FM}} \mathrm{r}_{\mathrm{w}}^{2} \mathrm{k}_{\mathrm{M}}}{\mathrm{k}_{\mathrm{F}}}$ \\
\hline F-f interporosity parameter & $\lambda_{\mathrm{Ff}}=\frac{\alpha_{\mathrm{Ff}} \mathrm{r}_{\mathrm{w}}^{2} \mathrm{k}_{\mathrm{f}}}{\mathrm{k}_{\mathrm{F}}}$ \\
\hline f-M interporosity parameter & $\lambda_{\mathrm{fM}}=\frac{\alpha_{\mathrm{fM}} \mathrm{r}_{\mathrm{w}}^{2} \mathrm{k}_{\mathrm{M}}}{\mathrm{k}_{\mathrm{f}}}$ \\
\hline F Storativity & $\omega_{\mathrm{F}}=\frac{\phi_{\mathrm{F}} \mathrm{C}_{\mathrm{F}}}{\phi_{\mathrm{m}} \mathrm{C}_{\mathrm{m}}+\phi_{\mathrm{f}} \mathrm{C}_{\mathrm{f}}+\phi_{\mathrm{F}} \mathrm{C}_{\mathrm{F}}}$ \\
\hline f Storativity & $\omega_{\mathrm{f}}=\frac{\phi_{\mathrm{f}} \mathrm{C}_{\mathrm{f}}}{\phi_{\mathrm{m}} \mathrm{C}_{\mathrm{m}}+\phi_{\mathrm{f}} \mathrm{C}_{\mathrm{f}}+\phi_{\mathrm{F}} \mathrm{C}_{\mathrm{F}}}$ \\
\hline M Storativity & $\omega_{\mathrm{M}}=\frac{\phi_{\mathrm{M}} \mathrm{C}_{\mathrm{M}}}{\phi_{\mathrm{m}} \mathrm{C}_{\mathrm{m}}+\phi_{\mathrm{f}} \mathrm{C}_{\mathrm{f}}+\phi_{\mathrm{F}} \mathrm{C}_{\mathrm{F}}}$ \\
\hline bles l & rs listed above \\
\hline
\end{tabular}




$$
\begin{gathered}
\mathrm{A}_{1}=\mathrm{A}_{0}+\frac{\lambda_{\mathrm{FM}}+\lambda_{\mathrm{Ff}}}{2 \omega_{\mathrm{F}}}+\left[\left(\mathrm{A}_{0}+\frac{\lambda_{\mathrm{FM}}+\lambda_{\mathrm{Ff}}}{2 \omega_{\mathrm{F}}}\right)^{2}-\frac{\mathrm{B}_{0}}{\omega_{\mathrm{F}}}\right]^{1 / 2} \\
\mathrm{~A}_{2}=\mathrm{A}_{0}+\frac{\lambda_{\mathrm{FM}}+\lambda_{\mathrm{Ff}}}{2 \omega_{\mathrm{F}}}-\left[\left(\mathrm{A}_{0}+\frac{\lambda_{\mathrm{FM}}+\lambda_{\mathrm{Ff}}}{2 \omega_{\mathrm{F}}}\right)^{2}-\frac{\mathrm{B}_{0}}{\omega_{\mathrm{F}}}\right]^{1 / 2} \\
\mathrm{~B}_{1}=\mathrm{A}_{0}+\left(\mathrm{A}_{0}^{2}-\mathrm{B}_{0}\right)^{1 / 2} \\
\mathrm{~B}_{2}=\mathrm{A}_{0}-\left(\mathrm{A}_{0}^{2}-\mathrm{B}_{0}\right)^{1 / 2} \\
\mathrm{~A}_{0}=\frac{1}{2}\left[\frac{\lambda_{\mathrm{FM}}}{\omega_{\mathrm{M}}}+\frac{\lambda_{\mathrm{Ff}}}{\omega_{\mathrm{f}}}+\left(\frac{1}{\omega_{\mathrm{M}}}+\frac{1}{\omega_{\mathrm{f}}}\right) \lambda_{\mathrm{fM}}\right] \\
\mathrm{B}_{0}=\frac{\lambda_{\mathrm{FM}} \lambda_{\mathrm{Ff}}+\left(\lambda_{\mathrm{FM}}+\lambda_{\mathrm{Ff}}\right) \lambda_{\mathrm{fM}}}{\omega_{\mathrm{M}} \omega_{\mathrm{f}}}
\end{gathered}
$$

According to Warren and Root (1963), flow through a double-porosity media can be sufficiently characterized by two parameters, storage parameter $\omega$ and interporosity parameter $\lambda$. The solution in Equation (9) indicates that the flow in the triple-continuum reservoir is characterized by five dimensionless parameters: $2 \omega$ 's and $3 \lambda$ 's (Table 2). Note that only two of the three $\omega$ 's are independent.

\subsection{Examination of Analytical Solutions}

In this section we examine the analytical solution [Equation (9)] and evaluates its accuracy in describing transient flow in the triple-continuum media using the numerical simulation results by the TOUGH2 code (Pruess, 1991; Wu et al., 1996).

The verification problem concerns typical transient flow towards a well that fully penetrates a radially infinite, horizontal, and uniformly fractured reservoir. In the numerical model, a radially finite reservoir $\left(\mathrm{r}_{\mathrm{e}}=10,000 \mathrm{~m}\right)$ is used and discretized into a one-dimensional (primary) grid. The distance $r_{e}(10,000 \mathrm{~m})$ is subdivided into 2,100 intervals following a logarithmic scale. A triple-continuum mesh is then generated from the primary grid, in which 
the one-dimensional, horizontal large-fracture plate network is assumed to be a uniform diskshaped matrix block. Fracture and matrix parameters are given in Table 3. Note that the values of these parameters are within the typical range of a triple-continuum model (i.e., $\mathrm{k}_{\mathrm{F}}$ $>>\mathrm{k}_{\mathrm{f}}>>\mathrm{k}_{\mathrm{m}}$ and $\phi_{\mathrm{m}} \gg>\phi_{\mathrm{f}} \gg \phi_{\mathrm{F}}$ ). The properties of large fractures and matrix correspond to those of the Prow Pass Tuff (PP2) at Yucca Mountain (Wu et al., 2000).

For this problem, many numerical tests and analyses have been performed to confirm the accuracy of these numerical simulation results, and here the numerical solutions are considered to be "exact" for comparison. Figure 4 presents a comparison of numerical modeling results (circles) with the approximate analytical solution (Equation 9, solid-line) using the input parameter values (Table 3). Excellent agreement exists between the two solutions, except for very small differences at very early times $\left(t_{D}<10\right.$ ). (Here a dimensionless time of $t_{D}=50$ corresponds to one second). The analytical solution, which is asymptotic and similar to the Warren-Root solution, may not itself be valid for $t_{D}<100$. The analytical solution may also introduce some errors at early times because it relies on the quasi-steady-state assumption for inter-continuum flow (Kazemi, 1969). Therefore the numerical solution is considered to be more accurate for small time values (Figure 4).

Many additional modeling comparisons have been performed with different parameters . In all cases, the analytical solution of Equation (9) was found to be very accurate for describing slightly compressible fluid flow through a triple-continuum system. Note that the numerical model used in this study includes global connections for the matrix continuum, which are not accounted for in the analytical solution. Figure 4 shows that ignoring matrix-matrix connections is a good approximation under single-phase flow conditions with normal fractured medium properties. In addition, we have examined effects of matrix-matrix connections by comparing the Warren-Root analytical solution with double-porosity and dual-permeability numerical model results. These comparisons indicate that matrix-matrix connections can be ignored for single-phase flow. 
Table 3. Parameters Used in the Single-Phase Flow Problem through the Triplecontinuum, Fractured Reservoir.

\begin{tabular}{|c|c|c|}
\hline Parameter & Value & Unit \\
\hline Matrix porosity & $\phi_{\mathrm{M}}=0.263$ & \\
\hline Large-fracture porosity & $\phi_{\mathrm{F}}=0.001$ & \\
\hline Small-fracture porosity & $\phi_{\mathrm{f}}=0.01$ & \\
\hline Large-fracture spacing & $A=5$ & $\mathrm{~m}$ \\
\hline Small-fracture spacing & $a=1.6$ & $\mathrm{~m}$ \\
\hline F characteristic length & $l_{x}=3.472$ & $\mathrm{~m}$ \\
\hline F-M/F-f areas per unit volume rock & $\mathrm{A}_{\mathrm{Ff}}=0.61$ & $\mathrm{~m}^{2} / \mathrm{m}^{3}$ \\
\hline Reference water density & $\rho_{\mathrm{i}}=1,000$ & $\mathrm{~kg} / \mathrm{m}^{3}$ \\
\hline Water phase viscosity & $\mu=1 \times 10^{-3}$ & Pa•s \\
\hline Matrix permeability & $\mathrm{k}_{\mathrm{M}}=1.572 \times 10^{-16}$ & $\mathrm{~m}^{2}$ \\
\hline Large-fracture permeability & $\mathrm{k}_{\mathrm{F}}=1.383 \times 10^{-13}$ & $\mathrm{~m}^{2}$ \\
\hline Small-fracture permeability & $\mathrm{K}_{\mathrm{f}}=1.383 \times 10^{-14}$ & $\mathrm{~m}^{2}$ \\
\hline Water Production Rate & $q=100$ & $\mathrm{M}^{3} / \mathrm{d}$ \\
\hline Total compressibility of three media & $\mathrm{C}_{\mathrm{F}}=\mathrm{C}_{\mathrm{M}}=\mathrm{C}_{\mathrm{f}}=1.0 \times 10^{-9}$ & $1 / \mathrm{Pa}$ \\
\hline Well radius & $\mathrm{r}_{\mathrm{w}}=0.1$ & $\mathrm{~m}$ \\
\hline F-M shape factor & $\alpha_{\mathrm{FM}}=0.480$ & $\mathrm{~m}^{-2}$ \\
\hline F-f shape factor & $\alpha_{\mathrm{Ff}}=0.351$ & $\mathrm{~m}^{-2}$ \\
\hline f-M shape factor & $\alpha_{\mathrm{fM}}=4.688$ & $\mathrm{~m}^{-2}$ \\
\hline F-M interporosity parameter & $\lambda_{\mathrm{FM}}=0.546 \times 10^{-6}$ & \\
\hline f-M interporosity parameter & $\lambda_{\mathrm{fM}}=0.533 \times 10^{-5}$ & \\
\hline F-f interporosity parameter & $\lambda_{\mathrm{Ff}}=0.480 \times 10^{-4}$ & \\
\hline F Storativity & $\omega_{\mathrm{F}}=0.0036$ & \\
\hline f Storativity & $\omega_{\mathrm{f}}=0.0365$ & \\
\hline M Storativity & $\omega_{\mathrm{M}}=0.9599$ & \\
\hline
\end{tabular}




\subsection{Discussion and Application of the Analytical Solutions}

The curve in Figure 4 exhibits three distinct straight parallel lines in semi-log space. This is typical behavior for flow through the triple-continuum model, and is similar to flow through a triple-porosity model (Wu and Ge, 1983). The first straight line, occurring at a very early time, represents pressure responses to high-permeability large fractures near the well. The second line (at intermediate times) reflects the effects of fluid storage in secondary permeable, small fractures on flow. In contrast, the third straight line portion (which corresponds to later-time flow behavior) is controlled by the high-storage, low-permeability matrix. However, depending on the fracture and matrix properties and the wellbore conditions (e.g., storage and skin effects), the first straight line may not develop or may occur too soon to be measured in a well test.

The analytical solution [Equation (9)] and the basic pattern of flow in triple-continuum media (Figure 4) suggest that it is possible to estimate small-fracture properties using traditional well-test techniques if at least two semi-log straight lines develop in a pressure buildup curve. Taking advantage of a property of the exponential integral, $\mathrm{E}_{\mathrm{i}}$ function:

$$
\left.\mathrm{E}_{\mathrm{i}}(\mathrm{x}) \approx \ln (\mathrm{x})+0.5775 \quad(\mathrm{x}<0.0025)\right)
$$

we can determine the four parameters, $\mathrm{A}_{1}, \mathrm{~A}_{2}, \mathrm{~B}_{1}$, and $\mathrm{B}_{2}$ (Table 2), subject to the condition:

$$
\mathrm{A}_{1}>\mathrm{B}_{1}>\mathrm{A}_{2}>\mathrm{B}_{2}
$$

Figure 5 defines several parameters: vertical distances (displacements) between the three semi-log straight lines $\left(\delta \mathrm{P}_{\mathrm{FM}}, \delta \mathrm{P}_{\mathrm{Ff}}\right.$, and $\left.\delta \mathrm{P}_{\mathrm{fM}}\right)$, and two pressure drops $\left(\mathrm{P}_{\mathrm{Ff}}^{*}\right.$ and $\left.\mathrm{P}_{\mathrm{fM}}^{*}\right)$ at transitional points between the semi-log straight lines. Applying Equations (10) and (11) to Equation (9) and using analogous analysis methods previously used for a double-porosity model (Earlougher, 1977), we derive the following expressions for estimating small-fracture porosity:

$$
\omega_{\mathrm{F}} \approx \exp \left(-\delta \mathrm{P}_{\mathrm{FM}} / \mathrm{m}\right)
$$




$$
\begin{gathered}
\frac{\phi_{\mathrm{F}} \mathrm{C}_{\mathrm{F}}}{\phi_{\mathrm{f}} \mathrm{C}_{\mathrm{f}}+\phi_{\mathrm{F}} \mathrm{C}_{\mathrm{F}}} \approx \exp \left(-\delta \mathrm{P}_{\mathrm{Ff}} / \mathrm{m}\right) \\
\frac{\phi_{\mathrm{f}} \mathrm{C}_{\mathrm{f}}}{\phi_{\mathrm{f}} \mathrm{C}_{\mathrm{f}}+\phi_{\mathrm{M}} \mathrm{C}_{\mathrm{M}}} \approx \exp \left(-\delta \mathrm{P}_{\mathrm{fM}} / \mathrm{m}\right)
\end{gathered}
$$

where $\mathrm{m}$ is the slope of the semi-log straight line (Figure 5), defined as:

$$
\mathrm{m}=\frac{\mathrm{q} \mathrm{\mu}}{4 \pi \mathrm{k}_{\mathrm{F}} \mathrm{h}}
$$

Similarly, we have the following relations for calculating small-fracture permeability:

$$
\ln \left(\frac{\mathrm{A}_{2}}{\mathrm{~B}_{0}}\right)+0.2319 \approx \mathrm{P}_{\mathrm{Ff}}^{*} / \mathrm{m}
$$

and

$$
-\ln \mathrm{B}_{2}+0.2319 \approx \mathrm{P}_{\mathrm{fM}}^{*} / \mathrm{m}
$$

Using the parameters listed in Table 3, we have confirmed that Equations (12) to (17) give good estimates for small-fracture properties. Equation (15) can be used to estimate the permeability of large fractures as long as a late-time semi-log straight line develops from a pressure drawdown or buildup curve from a well test.

Compared with small fractures, matrix and large-fracture properties are relatively easy to determine in the field using core samples of matrix rock and pneumatic or air-k data respectively. Equations (12)-(17) provide a methodology for estimating small-fracture parameters from well-pumping testing data under known matrix and large-fracture properties. Note that if only the second and third straight line develops, we can use Equations (14) and (17) to estimate the small-fracture properties.

\subsection{Tracer Transport Behavior under Single-Phase Flow Conditions}


In this section we study the transport behavior of a conservative tracer under single-phase conditions using a numerical simulator, the T2R3D code (Wu et al., 1996). The fracturematrix system under consideration is identical to the one-dimensional, radial flow problem of Section 4.2. However, we use both the triple-continuum and dual-permeability methods described above for comparison purposes. The transport problem is defined as a single-well tracer test with a pulse-tracer injection lasting 5 days. Throughout the tracer test, the flow remains at a steady-state condition while the volumetric well injection rate is maintained at $100 \mathrm{~m}^{3} / \mathrm{d}$. The fracture and matrix properties and fluid parameters used are also given in Table 3, with the exception that fracture properties in the dual-permeability model correspond to those for large fractures. In addition, we specifically select two scenarios to study the effect of fracture porosity in the two models. In the first scenario, fracture porosity for the dual-permeability model $\left(\phi_{\mathrm{f}, 2 \mathrm{k}}=0.0011\right)$ is set to be equal to the summation of the large-fracture and small-fractures porosities $\left(\phi_{\mathrm{F}}=0.000264\right.$ and $\left.\phi_{\mathrm{f}}=0.000836\right)$ for the triplecontinuum model. In the second scenario, fracture porosity $\left(\phi_{\mathrm{f}, 2 \mathrm{k}}=0.001\right)$ in the dualpermeability model is set equal to the large-fracture porosity $\left(\phi_{\mathrm{F}}=0.001\right)$ for the triplecontinuum model. In both cases, we ignore mechanical dispersion effects. The molecular diffusion coefficient for the tracer is $1.6 \times 10^{-10} \mathrm{~m}^{2} / \mathrm{s}$, and tortuosity for the three continua is 0.7 .

Figure 6 shows tracer breakthrough curves, observed at a location of $20 \mathrm{~m}$ away from the well, for the first scenario. In this case, the triple-continuum model predicts a much earlier breakthrough time than the dual-permeability model. This is because the solute transport is advection-dominated, and the flow along large fractures in the triple-continuum model is much faster than that through the fractures in the dual-permeability model $\left[\phi_{\mathrm{f}, 2 \mathrm{k}}(=0.0011)>\phi_{\mathrm{F}}(=0.000264)\right]$. In addition, interflow between different continua in both models tends to be very small under steady-state single-phase flow conditions. Consequently, the effects of the small fractures on the overall transport behavior are through diffusion only, which is a very slow process compared with advection. 
For the second scenario $\left(\phi_{\mathrm{f}, 2 \mathrm{k}}=\phi_{\mathrm{F}}=0.001\right)$, the breakthrough curves from the two models are almost identical (Figure 7). This is because the system is still dominated by advection, and the global fracture flow rates are very similar in the two models. In our simulations we alos reduced the well water injection rate by two-orders of magnitude and increased the molecular diffusion coefficient. In those cases, the triple-continuum model gives a slightly later breakthrough time than the dual-permeability model. This is due to the enhanced diffusion into the matrix (with the triple-continuum model) through the small fractures.

The tracer breakthrough curves (Figures 6 and 7) are sensitive to the fracture porosities in the triple-continuum model. This suggests that tracer tests may provide additional information regarding small-fracture porosity. For example, the tracer breakthrough curve can be used to distinguish contributions of large and small fractures to the measured fracture porosity.

\section{Model Application: Effects of Small Fractures on Flow and Transport in the UZ at Yucca Mountain}

This section demonstrates the applications of the present triple-continuum model for modeling flow and transport processes in the UZ of Yucca Mountain. Special attention is given to the potential effects of small fractures on UZ flow and transport. In this section, we present three application examples: (1) parameter estimation using field observation and inverse modeling studies, (2) three-dimensional mountain-scale model calibration (a flow and transport simulation) and (3) two-dimensional simulations of mountain-scale flow (transport and heat transfer simulations).

\subsection{Hydrogeologic Setting}

The UZ of Yucca Mountain, 500-700m thick, overlies a relatively flat water table in the vicinity of the potential repository area. The proposed repository would be located in the highly fractured Topopah Spring welded unit, more than $200 \mathrm{~m}$ above the water table. Yucca Mountain is a structurally complex system of Tertiary volcanic rock, consisting of 
alternating layers of welded and nonwelded ash flow and air fall tuffs. The primary geologic formations at Yucca Mountain (beginning from the land surface) consist of the Tiva Canyon, Yucca Mountain, Pah Canyon, and the Topopah Spring tuffs of the Paintbrush Group. Underlying these are the Calico Hills Formation, and the Prow Pass, Bullfrog, and Tram tuffs of the Crater Flat Group (Buesch et al., 1995). These geologic formations have been reorganized into several hydrogeologic units, based primarily on their degree of welding (Montazer and Wilson, 1984). These are the Tiva Canyon welded (TCw) hydrogeologic unit, the Paintbrush nonwelded (PTn) unit, the Topopah Spring welded (TSw) unit, the Calico Hills nonwelded ( $\mathrm{CHn})$ unit, and the Crater Flat undifferentiated $(\mathrm{CFu})$ unit.

The hydrogeologic units vary significantly in thickness over the model domain. In addition to the highly heterogeneous nature of the fractured tuffs at the mountain, there are numerous strike-slip and normal faults with varying amounts of offset (Scott and Bonk 1984; Day et al., 1998). These major faults generally penetrate through the complete $\mathrm{UZ}$ and to a certain extent control moisture flow and saturation distributions. These complex geological features are explicitly considered in the UZ models. Figure 8 shows a plan view of the site-scale UZ model grid, including the model domain, borehole locations, and the faults incorporated in the Yucca Mountain model.

\subsection{Parameter Estimation}

To model flow and transport in the UZ, we need to estimate the hydraulic properties of the small-scale fractures. In Section 4.3, we developed an approach to estimate smallscale fracture properties based on observations of single-phase flow (airflow in dry fractures or water flow in saturated fractures). However, the small-scale fracture property data determined using this approach are not currently available. In this section, we present a methodology to estimate small-scale fracture properties based on inverse modeling (Bandurraga and Bodvarsson, 1999). Due to data limitations, a number of assumptions are needed in order to employ this method . 
Although a considerable amount of fracture data has been mapped, most of these data do not include complete information about small-scale fractures (Liu et al., 2000). Recently, fracture mapping data (including all small fractures) have become available from a smallscale detailed line survey (DLS) (US Geological Survey, Unpublished Report) for the middle nonlithophysal unit (Tptpmn) and two other adjacent units. Analysis of this fracture data resulted in the following relations for Tptpmn unit:

$$
\begin{aligned}
& \frac{d_{f}}{d_{F}}=3.13 \\
& \frac{S_{f}}{S_{F}}=0.32 \\
& \frac{L_{f}}{S_{f}}=2.17
\end{aligned}
$$

where $\mathrm{d}, \mathrm{SP}$, and L refer to scanline fracture density (fracture $/ \mathrm{m}$ ), average fracture spacing $(\mathrm{m})$, and average trace length of fractures $(\mathrm{m})$, respectively. As before, the subscription $\mathrm{F}$ and $\mathrm{f}$ refer to large-scale and small-scale fractures, respectively. Here we assume that large-scale fractures are longer than $0.51 \mathrm{~m}$, as reported in Liu et al. (2000). The value of this "critical trace length" was determined empirically at Yucca Mountain where $80 \%$ of the fractures longer than $0.3 \mathrm{~m}$ are $0.51 \mathrm{~m}$ (Liu et al., 2000). To better distinguish between large-scale and small-scale fractures, more rigorous methods need to be developed in future studies. We further assumed that the porosities of the large-scale and small-scale fractures are proportional to their scanline densities $\left(\mathrm{d}_{\mathrm{f}}\right.$ and $\left.\mathrm{d}_{\mathrm{F}}\right)$. The total fracture porosity, as determined using available gas tracer data (Liu et al., 2000), is considered to include both large and small fractures for the triple-continuum model.

Because most of the geological units do not have mapped data for their small fractures, we assume that Equation (18) and the method discussed above can be used to estimate the fracture porosities for both large-scale and small-scale fractures for the other units. Note that the primary objective of this study is to evaluate the relative impact of small fractures on the flow and transport processes in the Yucca Mountain UZ. Since values for total fracture porosity, large-scale fracture spacing, and large-scale fracture density are now available for all the geologic units (Liu et al., 2000), the corresponding small-scale 
fracture properties can be easily determined. These property values are also needed for generating triple-continuum numerical grids.

Unsaturated flow in fractures is commonly characterized by fingering flow at different scales. This flow mechanism must be considered in order to accurately model flow and transport in fractured rock. Recently, Liu et al. (1998) proposed an active fracture model that incorporates fingering flow into the continuum approach. The active fracture model was used in this study to describe the flow and transport in fractures. Liu et al. (1998) divided the fracture continuum into two parts, active and inactive, to account for the fingering flow at the fracture-network scale. Flow and transport occurs only within the active fracture continuum, while the inactive part is simply bypassed. The portion of active fracture continuum relative to the whole fracture continuum $\left(f_{a}\right)$ is dynamic and assumed to be a power function of effective saturation $\left(\mathrm{S}_{\mathrm{e}}\right)$ within the fracture continuum (Liu et al., 1998):

$$
\mathrm{f}_{\mathrm{a}}=\mathrm{S}_{\mathrm{e}}{ }^{\gamma}
$$

where $\gamma$ is a constant (active fracture parameter). The active fracture model can be used for both the large-scale fracture continuum and the small-scale fracture continuum. For simplicity, we further assume that the two kinds of fracture continua have the same $\gamma$ value.

As a result of fingering flow at different scales, the effective interface area between fractures and the matrix is considerably smaller than the geometric interface area (Liu et al., 1998). The ratio of the effective interface area to the geometric interface area is called the interface area reduction factor $(\mathrm{R})$. Interface-area reduction also exists for interfaces between large-scale and small-scale fractures and between small-scale fractures and the matrix. The $\mathrm{R}$ expression for the interface between large-scale fracture and the matrix is given by Liu et al. (1998). It includes the effects stemming from the differences between active fracture spacing and geometric fracture spacing as determined from fracture maps. The pure reduction factor for interface area between large-scale fractures and the matrix, without considering the effects of differences between fracture spacings, is (Liu et al., 
1998),

$$
\mathrm{R}=\mathrm{S}_{\mathrm{e}}
$$

where $S_{e}$ is the effective saturation in the large-scale fractures. Because the interface area between large-scale and small-scale fractures is proportional to the interface area between large-scale fractures and the matrix (Figure 3), the R expression defined in (20) can be used for the interface between the two kinds of fractures. (In this case, the effective saturation for the large-scale fractures should be used for calculating R). Following the same logic used to derive Equation (20) (Liu et al., 1998), this equation can also be used for the interface between small-scale fractures and the matrix, as long as the effective saturation applies to the small-scale fractures.

The determination of hydraulic properties for small-scale fractures (using inverse modeling) involves matching 1-D simulation results to observed data collected from various boreholes (Figure 8). In this study, matrix saturation and water potential data collected from boreholes SD-12 and UZ-14 were used in the inversion. The properties determined from the inverse modeling are permeability and van Genuchten (1980) $\alpha$ (a measure of air entry value) for the small fractures in all the units. The other properties, such as relative permeabilities, are assumed to be the same as those for the large-scale fractures. During the inversion, properties for the matrix and large-scale fractures are set in accordance with the calibrated values given in Ahlers and Liu (2000). Figure 9 shows the comparison between simulated and observed matrix saturation distributions for a vertical column corresponding to borehole SD-12. As expected, the estimated permeability and $\alpha$ values for the small fractures generally fall between the values for the large-scale fractures and the matrix. For example, Table 4 shows the estimated smallscale-fracture properties for the Tsw34 unit as an example, compared with those for the matrix and the large-scale fractures. Estimated parameters are used in all the triplecontinuum simulations described in the following sections. 
Table 4 Small Fracture Properties for Tsw34.

\begin{tabular}{|l|l|l|l|}
\hline & Matrix & Small Fracture & Large Fracture \\
\hline Permeability $\left(\mathrm{m}^{2}\right)$ & $4.07 \mathrm{E}-18$ & $5.02 \mathrm{E}-16$ & $1.70 \mathrm{E}-11$ \\
\hline $\begin{array}{l}\text { Van Genuchten } \alpha \\
\left(\mathrm{Pa}^{-1}\right)\end{array}$ & $3.86 \mathrm{E}-6$ & $3.16 \mathrm{E}-4$ & $5.16 \mathrm{E}-4$ \\
\hline
\end{tabular}

\subsection{3-D Simulation of Flow and Transport}

The three-dimensional modeling studies described in this section are based on the current 3-D site-scale UZ flow model for the total system performance assessment (TSPA) (Wu et al., 2000). The aerial domain of the UZ model encompasses approximately $40 \mathrm{~km}^{2}$ of the Yucca Mountain area (Figure 8). The 3-D UZ model grid, as shown in Figure 8, has 1,324 mesh columns consisting of both fracture and matrix continua and 37 computational grid layers vertically, resulting in a total of 145,640 gridblocks and 492,098 connections for the triple-continuum grid.

Fracture-matrix interactions in the 3-D modeling are handled using the triple continuum methodology and are compared with results from the dual-permeability model. When applied to this study, the two fracture-matrix conceptual models are further modified by the active fracture model of Liu et al. (1998), as discussed in Section 5.2.

The model boundary conditions are specified as follows. The top model boundary is specified as the ground surface of the mountain; the bottom boundary lies at the water table level. Both top and bottom boundaries are Dirichlet-type while all of the lateral boundaries (Figure 8) are no-flow (laterally closed). In addition, net surface infiltration is applied to fracture blocks directly below the top boundary as source terms using the present-day, steady-state mean infiltration map, which is spatially varying and was previously estimated by the US Geological Survey (USGS) scientists (Hevesi and Flint, 2000) for the site. 
Properties for large fracture and matrix used for the triple-continuum model are the same as those for dual-permeability UZ flow model (Wu et al., 2000), and small-fracture properties are estimated in Section 5.2. In addition, the present triple-continuum model incorporates the permeability-barrier model in order to include the occurrence of perched water, as observed in the UZ. The rock properties designated in the triple-continuum model for the perched-water layers/zones are derived from the calibrated permeabilities for these areas (Wu et al., 2000).

Simulation results for steady-state UZ flow using the triple-continuum model are compared with (1) measured moisture data and (2) observed perched water bodies. For brevity, we show the model comparisons with observed data from boreholes SD-7, SD-9, SD-12 and UZ-14 (Figure 10). Figure 10 shows that the modeled results from the triplecontinuum simulation are in good agreement with both the measured saturation and the perched water elevations.

Figures 11 and 12 show the percolation fluxes at the repository and the water table levels, respectively, as simulated by the triple-continuum model. When comparing these results with those obtained using a dual-permeability model (Wu et al., 2000) under the same infiltration scenario and boundary conditions, we find that the flow patterns for the two models are similar. . This may indicate that small-fractures have little impact on global steady-state UZ flow because they are not globally connected. Note that large-fracture and matrix properties used in the triple-continuum model are the same as those for fractures and matrix in the dual-permeability model. This may also contribute to the similarity between the two model results.

In addition to the flow simulations for the triple-continuum model, we present model results for the transport of radionuclide tracers under a steady-state 3-D flow field. Transport simulations are conducted for both conservative and reactive tracers, using a decoupled version of the T2R3D code (Wu and Pruess, 2000). The 3-D steady-state flow 
field, discussed above, is directly used as an input to the T2R3D code for transport runs.

We consider two types of radionuclides: technetium (a conservative tracer) and neptunium (a reactive tracer). The initial conditions for the tracer transport simulations correspond to the ambient moisture conditions achieved when the flow field reaches a steady state. The two radionuclides are treated as nonvolatile and are transported through the liquid phase only. Radioactive decay and mechanical dispersion effects are ignored. A constant molecular diffusion coefficient of $3.2 \times 10^{-11}\left(\mathrm{~m}^{2} / \mathrm{s}\right)$ is used for diffusion of the conservative component and a diffusion coefficient of $1.6 \times 10^{-10}\left(\mathrm{~m}^{2} / \mathrm{s}\right)$ is used for the reactive component. In the case of a reactive or adsorbing tracer, several partitional coefficient, $K_{d}$, values are used (Table 5), which were selected to approximate those for neptunium $\left({ }^{237} \mathrm{~Np}\right)$ transport. All transport simulations were run to $1,000,000$ years under steady-state flow and constant initial source concentration conditions at the repository fracture blocks.

Table 5. $\quad \mathrm{K}_{\mathrm{d}}$ Values Used for a Reactive Tracer Transport in Different Hydrogeologic Units (Wu et al., 2000).

\begin{tabular}{|c|c|}
\hline Hydrogeologic Unit & $\begin{array}{c}\mathrm{K}_{\mathrm{d}} \\
(\mathrm{cc} / \mathrm{g})\end{array}$ \\
\hline Zeolitic matrix in CHn & 4.0 \\
\hline Vitric matrix in CHn & 1.0 \\
\hline matrix in TSw & 1.0 \\
\hline Fault matrix in CHn & 1.0 \\
\hline Fractures and the matrix in the rest of units & 0.0 \\
\hline
\end{tabular}

Tracer-transport behavior in UZ is analyzed using a cumulative or fractional breakthrough curve, as shown in Figure 13 for the present-day mean infiltration scenario. The fractional mass breakthrough in these figures is defined as the cumulative mass of the 
tracer (radionuclide) arriving at the entire bottom model boundary over time, normalized by the total initial mass of the tracer present at the repository. Figure 13 compares simulation results from the dual-permeability and triple-continuum models, showing that there is a significant difference between the simulated breakthrough curves. For example, a one-order-of-magnitude difference appears in the $20 \%$ breakthrough times for the nonsorbing radionuclide, Tc. Even for the sorbing radionuclide, Np, the $20 \%$ breakthrough times for the triple-continuum model results are twice those shown for the dual-permeability model.

The previous dual-permeability modeling studies of $\mathrm{Wu}$ et al. (2000) show that the factors that have the most important impact on tracer-transport times are surface infiltration rates, climate scenarios, and sorption effects. The transport results in Figure 13 indicate that the conceptual model for fracture-matrix interactions is also a very important factor and should be selected appropriately. Note that Figure 13 shows much longer transport times from the triple-continuum model as compared to those from the dual-permeability model. This behavior of predicted breakthrough times is entirely different from transport in the single-phase, triple-continuum medium of Section 4.4, in which the triple-continuum model predicted breakthrough times to be the same or less than those from the dual-permeability model. This result is primarily due to the nature of the unsaturated flow in the present triple-continuum simulation. Considerable flow still occurs between the large- and small- fractures and the matrix even under steady-state conditions, while little interaction between fracture-matrix systems can occur under single-phase, steady-state flow conditions. Secondly, the percolation fluxes with the 3-D model are much slower than the 1-D, radial flow at the well mainly because of the low infiltration rates at the site (several millimeters per years for the present-day climate). Therefore, diffusion plays a much more important role in the 3-D UZ transport result. In summary, because the triple-continuum model features a stronger interaction between the fractures and the matrix by both advection and diffusion, it predicts much longer transport times at the Yucca Mountain site. 
The above discussion is consistent with the findings of Bodvarsson et al. (2000) and Liu et al. (2001). They both indicate that matrix diffusion and other mechanisms related to solute transfer between the fractures and the matrix are the important factors controlling overall solute transport behavior within the UZ. In their study, Liu et al. (2001) would need to increase the fracture-matrix interface area in their dual-permeability model in order to match the field observed breakthrough curve. This increase is necessary to account for the effects of small fractures (Liu et al., 2001), which show a significant effect on solute transport (Figure 13).

\subsection{2-D Simulation of flow, Transport and Heat Transfer}

This section presents another application of the triple-continuum model, which involves 2-D simulation of unsaturated fluid flow, radionuclide transport, and heat transfer with repository thermal-loading effects. The 2-D model uses a more refined grid than the 3-D model for analyzing the impact of small fractures on flow and the transport processes at the site. Specifically, we compare simulation results from the triple-continuum model with those obtained from the dual-permeability model for the same 2-D cross section. The modeling study covers both ambient and elevated thermal conditions (due to the heat generated from high level nuclear waste emplacement in the repository drifts).

An east-west 2-D vertical cross section, crossing borehole UZ-14, is selected in this study (see Figure 8 for the borehole location). Figure 14 shows the 2-D primary grid, displaying geological layers, faults, and the potential repository layout along the east-west cross section. The 2-D model crosses the entire 3-D model domain laterally (Figure 8) and covers the entire UZ from the surface down to the water table. Relatively refined meshes are designed (Figure 14) for the cross section, with a grid spacing of $\Delta \mathrm{x}=40 \mathrm{~m}$ and $\Delta \mathrm{z} \leq 5$ $\mathrm{m}$. Faults are represented as vertical columns. The cross section characterized by the dualpermeability grid has 29,156 gridblocks and 74,546 connections, while the corresponding triple-continuum grid has 43,648 blocks and 103,490 connections. 
The modeling parameters used for the 2-D flow and transport simulation are the same as those used for the 3-D model $(\$ 5.2-5.3)$. In addition, the thermal properties used for the 2-D model from the site-scale thermal-hydrologic model (Haukwa, 2000). Boundary conditions used in the 2-D model are similar to those used in the 3-D model. The presentday, mean distributed surface infiltration map is implemented as source terms to the fracture gridblocks in the upper boundary. (The constant, spatial variation of the surface infiltration averages to $\sim 2.0 \mathrm{~mm} / \mathrm{yr}$ for the entire cross section). The flow simulation is carried out until steady state conditions are reached under ambient moisture and geothermal conditions, and then is used as the initial condition for the transport and heat flow runs.

Figure 15 compares steady-state percolation fluxes simulated at the repository level and the water table, respectively, and includes the surface infiltration rates along the cross section. As shown in Figure 15, the percolation pattern, predicted by the triple-continuum model, is almost the same as that by the dual-permeability model, which in turn is very similar to the 3-D model results (\$5.3). Comparisons of the flux distributions at the repository level and the water table with the surface infiltration pattern show that significant lateral flow occurs between the surface and the repository level (while the vertical faults act as flow-focusing paths).

Simulated cumulative breakthrough curves for a conservative tracer and a reactive tracer released from the repository blocks are shown in Figure 16. It shows that there is a more significant difference for 2-D conservative tracer transport (obtained from the triplecontinuum model and the dual-continuum model) than that resulting from the 3-D model for the same conservative tracer (Figures 13 and 16). The 2-D triple-continuum model shows that there is more than an order-of-magnitude slower breakthrough (for a relative concentration of 20\%) than that for the dual-permeability model. Figure 16 shows longer transport times compared with those in Figure 13 of the 3-D model because of the location of the cross section, which is underlain by thick low-permeability zeolitic layers in the $\mathrm{CHn}$ unit.. 
The study of heat transfer caused by thermal loading from radioactive waste emplacement within the repository blocks uses an average for mixed wastes (commercial and noncommercial spent fuels) that corresponds to an APD (Area Power Density) $=72.77$ $\mathrm{kW} / \mathrm{acre}$ for the base-case thermal loading scenario (Haukwa, 2000). The top model boundary is specified with constant, yet elevation-dependent temperatures, while the bottom temperature is set at $32^{\circ} \mathrm{C}$. The thermal load at the repository is introduced to the system as a decayed heat source in the repository matrix blocks at the middle of the 2-D model (Figure 14).

Figure 17 shows the changes in temperature versus time at three locations (i.e., the western, middle, and eastern end of the repository domain) within the 2-D model. The figure indicates a rapid increase in temperature at the repository after thermal load starts, only at the middle block temperature reaches close to the boiling point $\left(96^{\circ} \mathrm{C}\right)$ at ambient pressure about 100 years after waste emplacement. At the west and east ends, temperatures continue to rise at the repository to peak at $88^{\circ} \mathrm{C}$ after 30 years, but never reach the boiling point. After 100 years, the temperatures at the repository gradually decrease as net heat input is reduced. Note that the two fracture models predict almost the same temperature changes at the repository (Figure 17).

Figure 18 presents the spatial distribution of temperatures simulated along a vertical column at the middle of the 2-D cross section for different years. It is obvious from Figure 18 that the two fracture conceptual models again predict the same vertical thermal distributions under the same modeling conditions. In addition, we have examined other spatial distributions of simulated temperatures with the two models. These are also found to be very similar because the heat transfer from the repository blocks is dominated primarily by heat conduction and convection. Because of the smaller connecting areas (relative to contact in matrix rock mass) and the absence of global connections between small fractures, the effects of small fractures on global heat conduction may be negligible. Moreover, as we noted for the flow simulation results, small fractures contribute little to 
global flow fields, and thus have little impact on convection heat transfer. Therefore, it is adequate to characterize the thermal-hydrologic behavior of the repository using the dualpermeability model.

\section{Summary and Concluding Remarks}

We have developed a new triple-continuum conceptual model for modeling fluid flow, radionuclide transport, and heat transfer through heterogeneous fractured rocks. This new conceptual model takes into consideration that many of the fractures in a fractured system are not well-connected globally and it represents such a system with two different types of fracture continua and a matrix continuum. Using a generalized multiple-continuum approach, the model formulation uses three sets of conservation equations to describe the flow and transport processes at each location of the system, for the two fracture continua and one matrix continuum, respectively. The proposed triple-continuum model has been implemented into both analytical and numerical approaches. In particular, we have provided a methodology for using the triple-continuum concept to simulate processes of flow and transport in nonisothermal, multidimensional, multiphase, fractured reservoirs.

Several theoretical studies were performed with the triple-continuum conceptual fracture model, indicating that transient single-phase flow through a triple-continuum formation can be characterized by three parallel straight lines on semi-log plots of pressure versus time at a testing well. Based on this behavior, we developed several well-testing analysis equations for estimating small-fracture properties using transient well-testing techniques. In addition, tracer transport under single-phase flow conditions was found to provide an effective estimation of fracture porosity.

The proposed triple-continuum model has been applied to field problems at Yucca Mountain. First, we applied the new conceptual model to estimate model-related fracturematrix parameters using field observation data and an inverse-modeling approach. Then we incorporated the estimated parameters to perform 3-D site-scale flow and transport 
simulations with the current hydrogeological model of Yucca Mountain. The last example of the application was the investigation of a 2-D flow, transport, and heat transfer with a 2-D cross-section model. The 3-D and 2-D modeling results with the triple-continuum model indicate that small fractures have significant impact on radionuclide transport in the UZ system, but have insignificant impact on steady state unsaturated flow and heat transfer.

\section{Acknowledgments}

The authors would like to thank C. Doughty and J. Liu for their review of the manuscript. Thanks are also due to J. Liu and L. Pan for their help in this work. This work was in part supported by the Director, Office of Civilian Radioactive Waste Management, U.S. Department of Energy, through Memorandum Purchase Order EA9013MC5X between Bechtel SAIC Company, LLC and the Ernest Orlando Lawrence Berkeley National Laboratory (Berkeley Lab). The support is provided to Berkeley Lab through the U.S. Department of Energy Contract No. DE-AC03-76SF00098

\section{TABLE OF NOMENCLATURE}

a

A

$\mathrm{A}_{0}, \mathrm{~A}_{1}, \mathrm{~A}_{2}$

$\mathrm{A}_{\mathrm{Ff}}$

$\mathrm{A}_{\mathrm{nm}}$

$\mathrm{b}$

$\mathrm{B}$

$\mathrm{B}_{0}, \mathrm{~B}_{1}, \mathrm{~B}_{2}$

$\mathrm{c}$

$\mathrm{C}$

$\mathrm{C}_{\mathrm{f}}$

$\mathrm{C}_{\mathrm{F}}$

$\mathrm{C}_{\mathrm{M}}$

$\mathrm{d}_{\mathrm{f}}$

$d_{F}$

$d_{m}$ small-fracture spacing along large fracture or the $\mathrm{x}$-direction $(\mathrm{m})$ large-fracture spacing along large fracture or the $\mathrm{x}$-direction $(\mathrm{m})$ parameters for the analytical solution (Table 2)

total combined area of large fracture and small fracture connections per unit volume of rock $\left(\mathrm{m}^{2} / \mathrm{m}^{3}\right)$

interface areas between two elements $n$ and $m\left(\mathrm{~m}^{2}\right)$

small-fracture spacing along large-fracture or the y-direction $(\mathrm{m})$ large-fracture spacing along large-fracture or the y-direction (m) parameters for the analytical solution (Table 2)

small-fracture spacing along large fracture or the z-direction (m) large-fracture spacing along large fracture or the $\mathrm{z}$-direction $(\mathrm{m})$ total compressibility in small-fracture continuum $\left(\mathrm{Pa}^{-1}\right)$ total compressibility in large-fracture continuum $\left(\mathrm{Pa}^{-1}\right)$ total compressibility in matrix continuum $\left(\mathrm{Pa}^{-1}\right)$

large-fracture density (fractures $/ \mathrm{m}$ )

small-fracture density (fractures $/ \mathrm{m}$ )

molecular diffusion coefficient $\left(\mathrm{m}^{2} / \mathrm{s}\right)$ of a component in a fluid phase 


\begin{tabular}{|c|c|}
\hline$\underline{\mathrm{D}}_{\beta}^{\mathrm{\kappa}}$ & $\begin{array}{l}\text { effective hydrodynamic dispersion tensor accounting for both } \\
\text { molecular diffusion and mechanical dispersion for component } \kappa \text { in } \\
\text { phase } \beta\left(\mathrm{m}^{2} / \mathrm{s}\right)\end{array}$ \\
\hline f & denotes small fracture \\
\hline $\mathrm{F}$ & denotes large fracture \\
\hline$f_{a}$ & reduction factor of fracture-matrix interfaces \\
\hline $\mathrm{F}_{\mathrm{nm}}^{(\kappa), \mathrm{k}+1}$ & $\begin{array}{l}\text { flow components of mass }(\kappa)\left(\mathrm{kg} / \mathrm{s} / \mathrm{m}^{2}\right) \text { or energy }\left(\mathrm{W} / \mathrm{m}^{2}\right) \text { flow } \\
\text { along connection nm of time level } \mathrm{k}+1\end{array}$ \\
\hline $\mathrm{h}$ & thickness of formation $(\mathrm{m})$ \\
\hline $\mathrm{h}_{\beta}$ & specific enthalpy of phase $\beta(\mathrm{J} / \mathrm{kg})$ \\
\hline $\mathrm{h}_{\beta}^{\kappa}$ & specific enthalpy of component $\kappa$ in phase $\beta(\mathrm{J} / \mathrm{kg})$ \\
\hline $\mathrm{k}_{\mathrm{F}}$ & absolute permeability of large fracture continuum $\left(\mathrm{m}^{2}\right)$ \\
\hline $\mathrm{k}_{\mathrm{f}}$ & absolute permeability of small fracture continuum $\left(\mathrm{m}^{2}\right)$ \\
\hline $\mathrm{k}_{\mathrm{M}}$ & absolute permeability of matrix continuum $\left(\mathrm{m}^{2}\right)$ \\
\hline $\mathrm{K}_{\mathrm{d}}^{\kappa}$ & distribution coefficient of component $\kappa$ between the liquid phase \\
\hline & and rock solids of fractures and matrix $\left(\mathrm{m}^{3} / \mathrm{kg}\right)$ \\
\hline $\mathrm{K}_{\text {th }}$ & rock thermal conductivity $\left(\mathrm{W} / \mathrm{m}^{\circ} \mathrm{C}\right)$ \\
\hline$l_{f}, l_{F}$ & $\begin{array}{l}\text { characteristic length }(\mathrm{m}) \text { of small and large fractures in the } \mathrm{x}- \\
\text { direction and the } \mathrm{y} \text {-direction, respectively }\end{array}$ \\
\hline$l_{F f}, l_{F M}, l_{f M}$ & $\begin{array}{l}\text { characteristic distance }(\mathrm{m}) \text { between F-f, F-M, and } \mathrm{f}-\mathrm{M} \text {, } \\
\text { respectively, (defined in Table (1) }\end{array}$ \\
\hline $\mathrm{L}_{\mathrm{f}}$ & average trace length of small fractures $(\mathrm{m})$ \\
\hline$l_{x}, l_{y}$ & $\begin{array}{l}\text { half-length }(\mathrm{m}) \text { of small fractures, respectively, (defined in Table } 3 \\
\text { and illustrated in Figures } 2 \text { and } 3 \text { ) }\end{array}$ \\
\hline $\mathrm{m}$ & slope of semi-log straight lines of pressure versus time curves \\
\hline M & denotes matrix \\
\hline $\mathrm{M}_{\mathrm{n}}^{\mathrm{k}, \mathrm{k}+1}$ & $\begin{array}{l}\text { accumulation terms for mass component }(\kappa)\left(\mathrm{kg} / \mathrm{m}^{3}\right) \text { or energy } \\
\left(\mathrm{J} / \mathrm{m}^{3}\right) \text { of gridblock } \mathrm{n} \text { at time level } \mathrm{k}+1\end{array}$ \\
\hline $\mathrm{P}_{\mathrm{D}}$ & dimensionless pressure in fracture continuum \\
\hline$P_{j}$ & pressure $(\mathrm{Pa})$ in continuum $\mathrm{j}(\mathrm{j}=\mathrm{F}, \mathrm{f}$, and $\mathrm{M})$ \\
\hline $\mathrm{P}_{\mathrm{Ff}}^{*}, \mathrm{P}_{\mathrm{fM}}^{*}$ & measured pressures $(\mathrm{Pa})$ at transitional points between large \\
\hline & $\begin{array}{l}\text { fracture to small fracture and between small fracture to matrix, } \\
\text { respectively }\end{array}$ \\
\hline$\delta \mathrm{P}_{\mathrm{FM}}, \delta \mathrm{P}_{\mathrm{Ff}}, \delta \mathrm{P}_{\mathrm{fM}}$ & vertical pressure distances (displacements) (Pa) of three semi-log \\
\hline & $\begin{array}{l}\text { straight lines, between first and third, first and second, and second } \\
\text { and third straight lines, respectively }\end{array}$ \\
\hline$q^{E}$ & source/sink or fracture-matrix interaction terms for energy $\left(\mathrm{W} / \mathrm{m}^{3}\right)$ \\
\hline $\mathrm{q}^{\kappa}$ & $\begin{array}{l}\text { source/sink or fracture-matrix interaction of mass for component } \kappa \\
\left(\mathrm{kg} / \mathrm{s} \mathrm{m}^{3}\right)\end{array}$ \\
\hline $\mathrm{q}_{\mathrm{n}}^{\mathrm{k}, \mathrm{k}+1}$ & source/sink or fracture-matrix exchange terms for component $\kappa$ at \\
\hline
\end{tabular}


$\mathrm{R}$

$\mathrm{R}_{\mathrm{n}}^{\mathrm{\kappa}, \mathrm{k}+1}$

$\mathrm{r}_{\mathrm{w}}$

$\mathrm{S}_{\mathrm{e}}$

$\mathrm{S}_{\beta}$

$\mathrm{SP}_{\mathrm{f}}$

$\mathrm{SP}_{\mathrm{F}}$

$\mathrm{t}$

$\Delta \mathrm{t}$

$\mathrm{T}$

$t_{D}$

$\mathrm{U}_{\beta}$

$\mathrm{U}_{\mathrm{s}}$

$\mathrm{V}_{\mathrm{n}}$

$\mathbf{v}_{\beta}$

$\mathrm{X}_{\beta}^{\kappa}$

element $\mathrm{n}\left(\mathrm{kg} / \mathrm{s} \mathrm{m}^{3}\right)$ of time level $\mathrm{k}+1$

fracture-matrix area reduction factor

residual term of mass balance of component $\left(\mathrm{kg} / \mathrm{m}^{3}\right)$ and energy $\left(\mathrm{J} / \mathrm{m}^{3}\right)$ balance at element $\mathrm{n}$ of time level $\mathrm{k}+1$

well radius $(\mathrm{m})$

effective liquid saturation

fluid saturation of phase $\beta$

average spacing of small fractures (m)

average spacing of large fractures (m)

time (s)

time step (s)

temperature $\left({ }^{\circ} \mathrm{C}\right)$

dimensionless time (defined in Table 2)

internal energy of phase $\beta(\mathrm{J} / \mathrm{kg})$

internal energy of rock solids $(\mathrm{J} / \mathrm{kg})$

volume of element $\mathrm{n}\left(\mathrm{m}^{3}\right)$

Darcy's velocity of phase $\beta(\mathrm{m} / \mathrm{s})$

mass fraction of component $\kappa$ in phase $\beta$.

\section{GREEK SYMBOLS}

$\alpha_{\mathrm{Ff}}$

$\alpha_{\mathrm{FM}}$

$\alpha_{\mathrm{fM}}$

$\phi_{\mathrm{f}}$

$\phi_{\mathrm{F}}$

$\phi_{\mathrm{M}}$

$\gamma$

$\lambda_{\text {Ff }}$

$\lambda_{\mathrm{FM}}$

$\lambda_{\mathrm{fM}}$

$\lambda_{\kappa}$

$\mu$

$\rho$

$\rho_{\mathrm{i}}$

$\rho_{\beta}$ shape factor $\left(\mathrm{m}^{-2}\right)$ of governing interflow between large fracture and small fracture

shape factor $\left(\mathrm{m}^{-2}\right)$ of governing interflow between large fracture and matrix

shape factor $\left(\mathrm{m}^{-2}\right)$ of governing interflow between small fracture and matrix

effective porosity of small fracture continuum

effective porosity of large fracture continuum

effective porosity of matrix continuum

active fracture parameter

F-M interporosity parameter (defined in Table 2)

F-f interporosity parameter (defined in Table 2)

$\mathrm{f}-\mathrm{M}$ interporosity parameter (defined in Table 2)

radioactive decay constant of the chemical species $\kappa\left(\mathrm{s}^{-1}\right)$

viscosity of fluid (Pa•s)

density of fluid at in-situ conditions $\left(\mathrm{kg} / \mathrm{m}^{3}\right)$

density of fluid at reference or initial conditions $\left(\mathrm{kg} / \mathrm{m}^{3}\right)$

density of phase $\beta$ at in situ conditions $\left(\mathrm{kg} / \mathrm{m}^{3}\right)$ 


$\begin{array}{ll}\rho_{\mathrm{s}} & \text { density of rock grains }\left(\mathrm{kg} / \mathrm{m}^{3}\right) \\ \omega_{\mathrm{f}} & \text { f storativity ratio (defined in Table 2) } \\ \omega_{\mathrm{F}} & \text { F storativity ratio (defined in Table 2) } \\ \omega_{\mathrm{M}} & \mathrm{M} \text { storativity ratio (defined in Table 2). }\end{array}$

\section{SUBSCRIPTS}

$\begin{array}{ll}\text { e } & \text { effective } \\ \mathrm{f} & \text { small fracture } \\ \mathrm{F} & \text { large fracture } \\ \mathrm{M} & \text { matrix } \\ \mathrm{S} & \text { rock solid or surface ratio } \\ \text { th } & \text { thermal } \\ \beta & \text { index for fluid phase. }\end{array}$

\section{SUPERSCRIPTS}

$\begin{array}{ll}\mathrm{E} & \text { energy } \\ \kappa & \text { index for mass components. }\end{array}$

\section{References}

Abdassah, D., Ershaghis I., 1986. Triple-porosity System for Representing Naturally Fractured Reservoirs, SPE Form. Eval., 1, 113-127.

Ahlers, C.F., Liu, H.H., 2000. Calibrated Properties Model. Report MDL-NBS-HS000003. Berkeley, California: Lawrence Berkeley Laboratory. Las Vegas, Nevada: CRWMS $\mathrm{M} \& \mathrm{O}$.

Ahlers C.F., Bandurraga, T.M., Bodvarsson, G.S., Chen, G., Finsterle, S. and Wu, Y.S., 1995. Performance analysis of the LBNL/USGS Three-Dimensional Unsaturated Zone Site-Scale Model, Yucca Mountain Project Milestone 3GLM105M, Lawrence Berkeley National Laboratory, Berkeley, CA.

Bai, M., Elsworth, D., Roegiers, J.C., 1993. Multiporosity/Multipermeability Approach to the Simulation of Naturally Fractured Reservoirs, Water Resour. Res. 29, 1621-1633.

Banddurraga, T.M., Bodvarsson, G.S., 1999. Calibrating Hydrologeologic Parameters for the 3-D Site-Scale Unsaturated Zone Model of Yucca Mountain, Nevada, Journal of Contaminant Hydrology, 38(1-3), 25-46.

Barenblatt, G.I., Zheltov, I.P., Kochina, I.N., 1960. Basic Concepts in the Theory of Seepage of Homogeneous Liquids in Fissured Rocks, PMM, Sov. Appl. Math. Mech., 24(5), 852-864.

Bodvarsson, G.S., Liu, H.H., Ahlers, R., Wu, Y.S., Sonnethal, E., 2000. Parameterization and upscaling in modeling flow and transport at Yucca Mountain, in Conceptual Models of Flow and 
Transport in the Fractured Vadose Zone, NRC/NAS Workshop Irvine, California.

Buesch, D.C., Spengler, R.W., Nelson, P.H., Vaniman, D.T., Chipera, S.J., Bish, D.L., 1995. Geometry of the Vitric-Zeolitic Transition in Tuffs and the Relation to Fault Zones at Yucca Mountain, Nevada. International Union of Geodesy and Geophysics, XXI General Assembly, July 2-14, 1995.

Closemann, P.J., 1975. The Aquifer Model for Fissured Fractured Reservoir, Soc. Pet. Eng. J., 385-398.

Day, W.C., Potter, C.J., Sweetkind, D.E., Dickerson, R.P., San Juan, C.A., 1998. Bedrock Geologic Map of the Central Block Area, Yucca Mountain, Nye County, Nevada. Map I-2601. Washington, D.C.: U.S. Geological Survey.

Doughty, C. 1999. Investigation of Conceptual and Numerical Approaches for Evaluating Moisture, Gas, Chemical, and Heat Transport in Fractured Unsaturated Rock, Journal of Contaminant Hydrology, 38(1-3), 69-106.

Earlougher, R.C. Jr., 1977. Advances in Well Test Analysis, SPE Monograph, Vol. 5, SPE of AIME, Dallas.

Haukwa, C., 2000. Maintain-Scale Coupled Process (TH) Model. Report TDP-NBS-HS-100012. Berkeley, California: Lawrence Berkeley Laboratory. Las Vegas, Nevada: REV 00 CRWMS $\mathrm{M} \& \mathrm{O}$.

Hevesi, J., Flint, L., 2000. Simulation of Net Infiltration for Modern and Potential Future Climate. Report ANL-NBS-GS-000008. Denver, Colorado: U. S. Geological Survey.

Kazemi, H., 1969. Pressure Transient Analysis of Naturally Fractured Reservoirs with Uniform Fracture Distribution. SPEJ, 451-62. Trans., AIME, 246.

Liu, H.H., Ahlers, C.F., Cushey, M.A., 2000. Analysis of Hydrologic Properties. Report ANLNBS-HS-000002. Berkeley, California: Lawrence Berkeley Laboratory. Las Vegas, Nevada: CRWMS M\&O.

Liu, H.H., Doughty, C., Bodvarsson, G.S., 1998. An active fracture model for unsaturated flow and transport in fractured rocks, Water Resource Research, 34, 2633-2646.

Liu, H.H., Haukwa, C.B., Ahlers, C.F., Bodvarsson, G.S., Flint, A.L., Guertal W.B., 2001. Modeling flow and transport in unsaturated fractured rocks: An evaluation of the continuum approach, to be submitted to Journal of Contaminant Hydrology.

Liu, J.C. Bodvarsson, G.S., and Wu, Y.S., 2001. Analysis of pressure behavior in fractured lithophysal reservoirs, to be submitted to Journal of Contaminant Hydrology.

McLaren, R.G., Forsyth, P.A., Sudicky, E.A., VanderKwaak, J.E., Schwarltz, F.W., Kessler, J.H., 2000. Flow and Transport in Fractured Tuff at Yucca Mountain: Numerical Experiments on Fast Preferential Flow Mechanisms, Journal of Contaminant Hydrology. 43, 211-238. 
Montazer, P., Wilson, W.E., 1984. Conceptual Hydrologic Model of Flow in the Unsaturated Zone, Yucca Mountain, Nevada. Water-Resources Investigations Report 84-4345. Lakewood, Colorado: U.S. Geological Survey.

Pollock, D.W., 1986. Simulation of fluid flow and energy transport processes associated with high-level radioactive waste disposal in unsaturated alluvium, Water Resour. Res., 22(5), 765775 .

Pruess K., 1991. TOUGH2-A General Purpose Numerical Simulator for Multiphase Fluid and Heat Flow, Report LBL-29400, UC-251. Berkeley, California: Lawrence Berkeley National Laboratory.

Pruess, K., Narasimhan, T.N., 1985. A Practical Method for Modeling Fluid and Heat Flow in Fractured Porous Media, Soc. Pet. Eng. J., 25, 14-26.

Pruess, K., 1983. GMINC - A Mesh Generator for Flow Simulations in Fractured Reservoirs, Report LBL-15227, Berkeley, California: Lawrence Berkeley National Laboratory.

Rulon, J., Bodvarsson, G.S., Montazer, P., 1986. Preliminary Numerical Simulations of Groundwater Flow in the Unsaturated Zone, Yucca Mountain, Nevada. LBL-20553. Berkeley, California: Lawrence Berkeley Laboratory.

Scott, R.B., Bonk, J., 1984. Preliminary Geologic Map of Yucca Mountain, Nye County, Nevada, with Geologic Sections. Open-File Report 84-494. Denver, Colorado: U.S. Geological Survey.

Snow, D.T., 1965. A Parallel Plate Model of Fractured Permeable Media, Ph.D. Dissertation, 331. pp., University of California, Berkeley. (ADD INFO???)

Sudicky, E.A., McLaren, R.G., 1992. Users's Guide for Fractran: An Efficient Simulators for Two-dimensional, Saturated Groundwater Flow and Solute Transport in Poropus or Discretelyfractured Porous Formations, Groundwater Simulations Group, Institute for Groundwater Research, university of Waterloo, Waterloo, Ontario, Canada N2L 3G1.

Tsang, Y.W., Pruess, K., 1987. A study of thermally induced convection near a high-level nuclear waste repository in partially saturated fracture tuff, Water Resour. Res., 23(10), 19581966.

van Genuchten, M. Th., 1980. A Closed-Form Equation for Predicting the Hydraulic Conductivity of Unsaturated Soils, Soil Sci. Soc. Amer. J, 44(5), 892-898.

Warren, J.E., Root, P.J., 1963. The Behavior of Naturally Fractured Reservoirs, Soc. Pet. Eng. J., 245-255, Transactions, AIME, 228.

Wittwer, C., Chen, G., Bodvarsson, G.S., Chornack, M., Flint, A., Flint, L., Kwicklis, E., Spengler, R., 1995. Preliminary Development of the LBL/USGS Three-Dimensional Site-Scale Model of Yucca Mountain, Nevada. LBL-37356. Berkeley, California: Lawrence Berkeley Laboratory.

Wu, Y.S., 2000. On the Effective Continuum Method for Modeling Multiphase Flow, Multicomponent Transport and Heat Transfer in Fractured Rock, "Dynamics of Fluids in 
Fractured Rocks, Concepts and Recent Advances", Edited by B. Faybishenko, P. A. Witherspoon and S. M. Benson, AGU Geophysical Monograph 122, American Geophysical Union, Washington, DC, 299-312.

Wu, Y.S., Liu, J. Xu, T., Haukwa, C., Zhang, W., Liu, H.H., Ahlers, C.F., 2000. UZ flow models and submodels, Report MDL-NBS-HS-000006, Lawrence Berkeley National Laboratory, CRWMS M\&O.

Wu, Y.S., Pruess, K., 2000. Numerical Simulation of Non-Isothermal Multiphase Tracer Transport in Heterogeneous Fractured Porous Media, Advance in Water Resources, 23, 699-723.

Wu, Y.S., Haukwa, C., Bodvarsson, G.S., 1999. A Site-Scale Model for Fluid and Heat Flow in the Unsaturated Zone of Yucca Mountain, Nevada, Journal of Contaminant Hydrology, 38(1-3), $185-215$.

Wu, Y.S., Ritcey, A.C., Ahlers, C.F., Hinds, J., Mishra, A.K., Haukwa, C., Liu, H.H., Sonnenthal, E.L., Bodvarsson, G.S., 1998. 3-D UZ Site-Scale Model for Abstraction in TSPAVA, Yucca Mountain Project Level 4 Milestone Report SLX01LB3, Lawrence Berkeley National Laboratory, Berkeley, CA.

Wu, Y.S., Ahlers, C.F., Fraser, P., Simmons, A., Pruess, K., 1996. Software qualification of selected TOUGH2 modules, Report LBNL-39490, Lawrence Berkeley National Laboratory, Berkeley, CA.

Wu, Y.S., Haukwa, C., Bodvarsson, G.S., 1999. A Site-Scale Model for Fluid and Heat Flow in the Unsaturated Zone of Yucca Mountain, Nevada. Journal of Contaminant Hydrology. 38(1-3), $185-217$.

Wu, Y.S., K. Pruess, 1988. A multiple-porosity method for simulation of naturally fractured petroleum reservoirs, SPE Reservoir Engineering, 3, 327-336.

Wu, Y.S., Ge, J.L., 1983. The Transient Flow in Naturally Fractured Reservoirs with Three-Porosity Systems, Acta, Mechanica Sinica, Theoretical and Applied Mechanics, Beijing, China, 15(1), 81-85. 


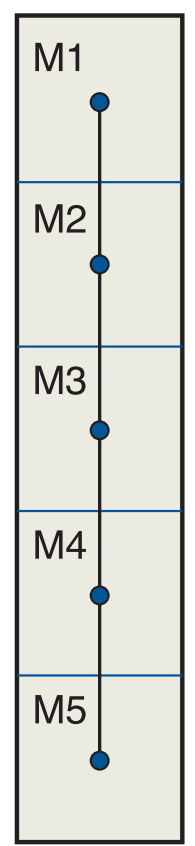

(a)

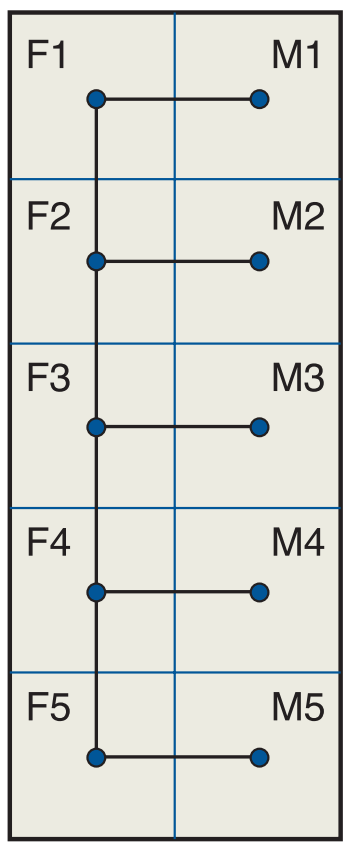

(b)

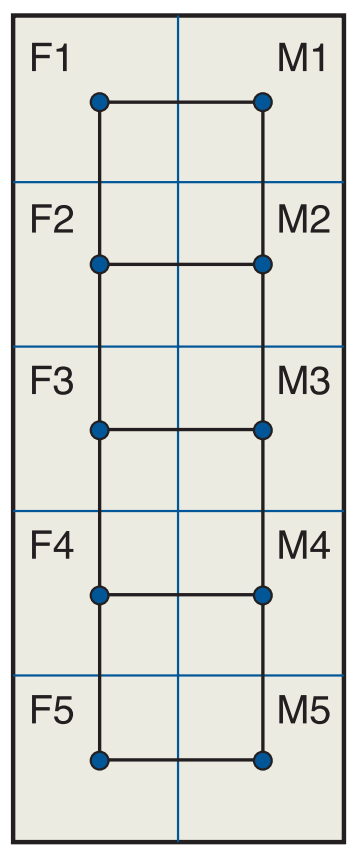

(c)

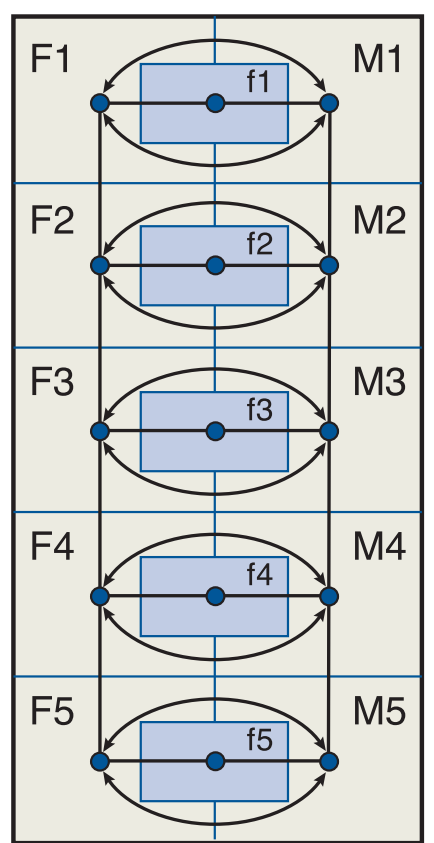

(d)

- Block Center

Connection

UZ01-010

Figure 1. Schematic of different conceptualizations for handling fracture-matrix interactions: (a) effective-continuum model (ECM); (b) double-porosity model; (c) dualpermeability model; and (d) triple-continuum model. ( $\mathrm{M}=$ matrix; $\mathrm{F}=$ large-fractures; $\mathrm{f}=$ small-fractures). 

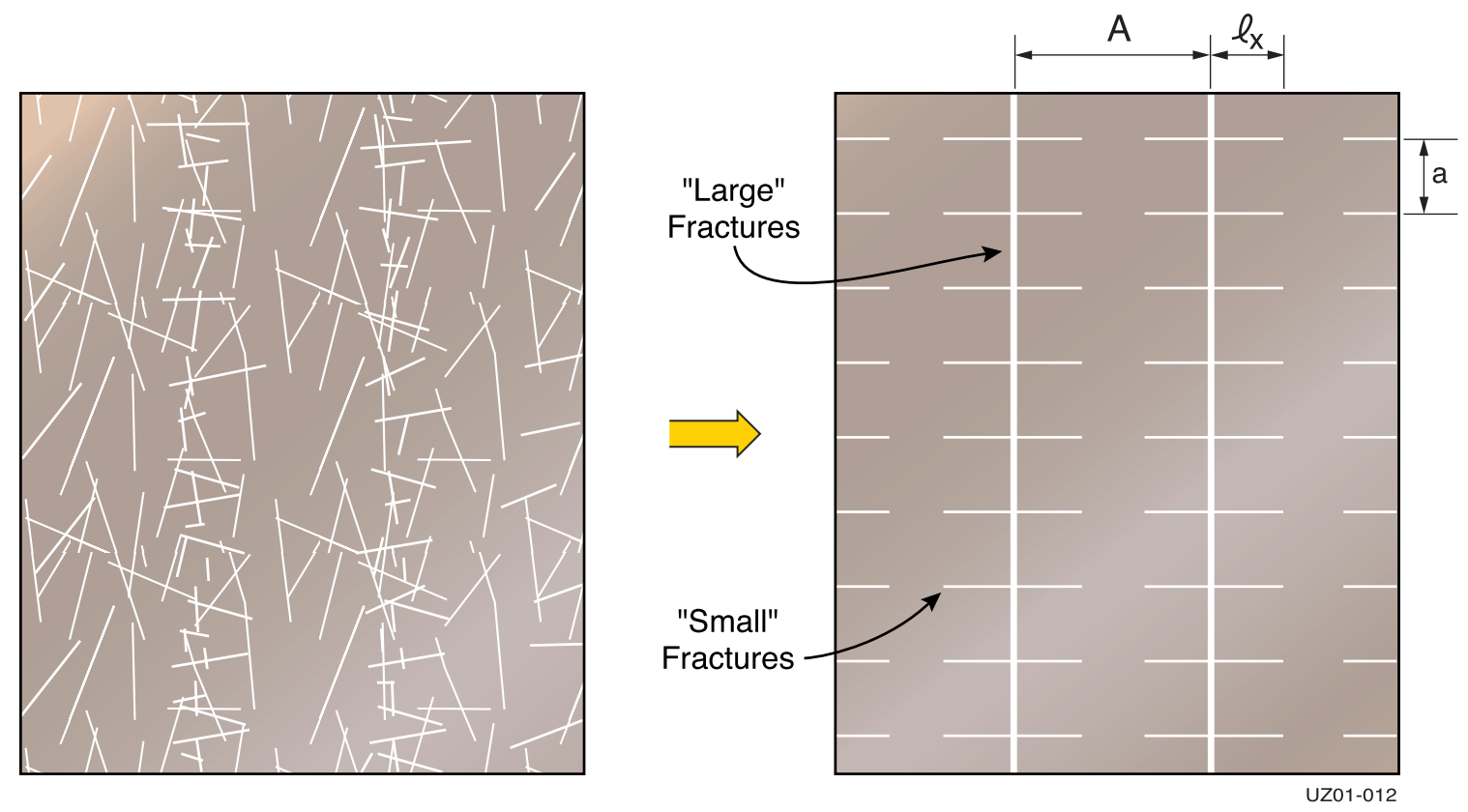

Figure 2. Basic conceptualization for triple-continuum approximation of one-dimensional large-fracture, small-fracture, and rock matrix systems. 

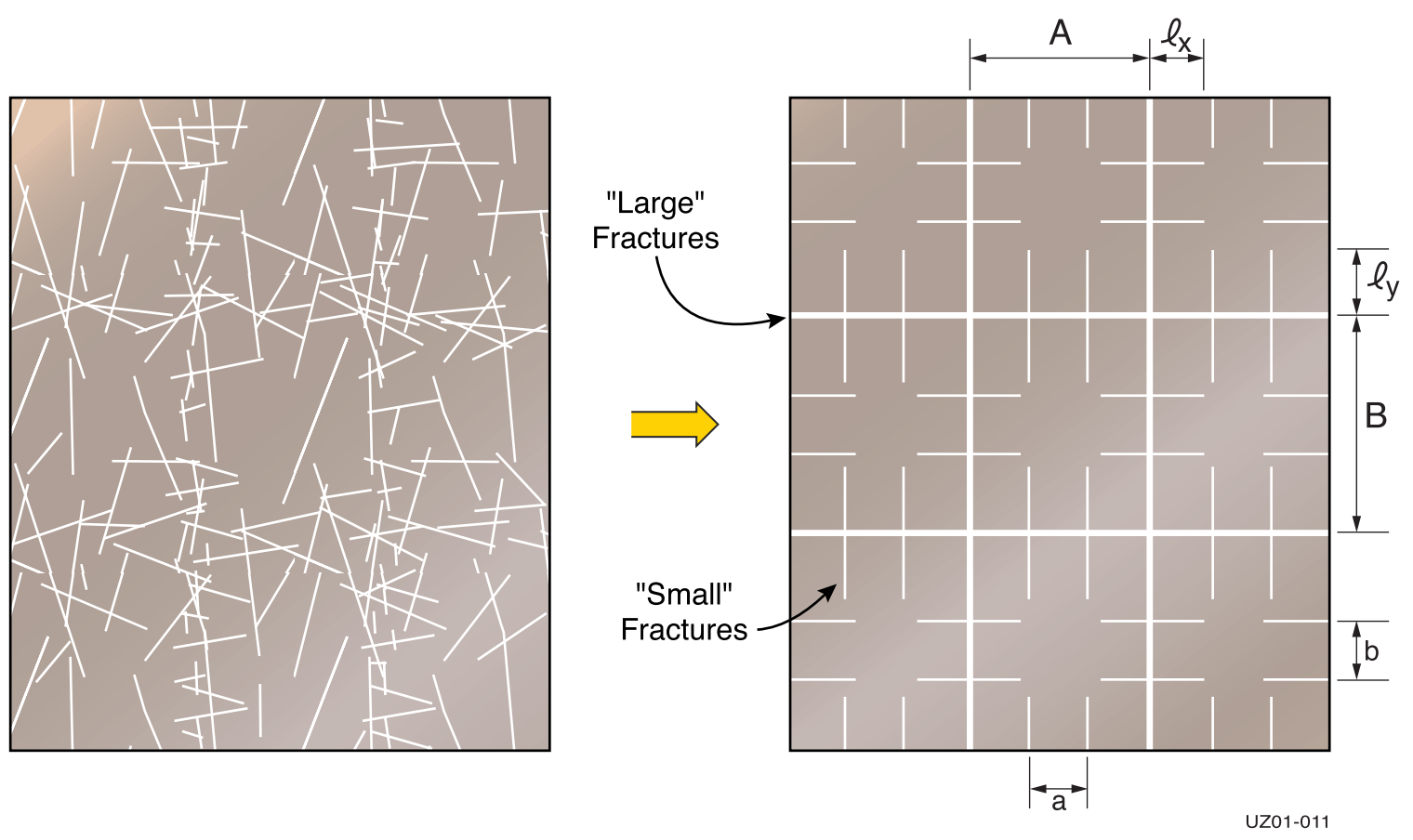

Figure 3. Basic conceptualization for triple-continuum approximation of two-dimensional large-fracture, small-fracture, and rock matrix systems. 


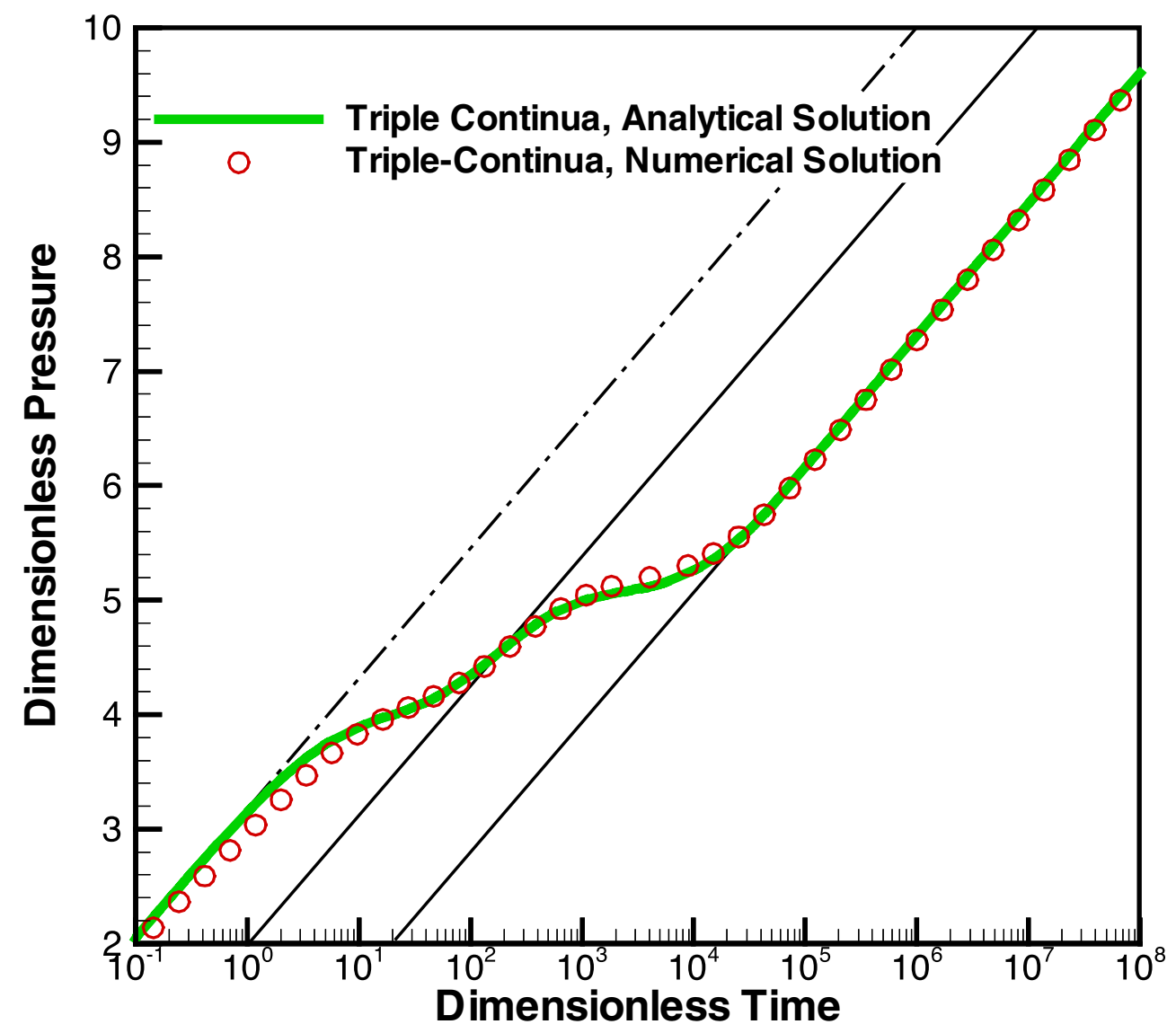

UZ01-014

Figure 4. Typical behavior curve of flow through a triple-continuum fracture medium, showing three-parallel semi-log straight lines from effects of three continua 


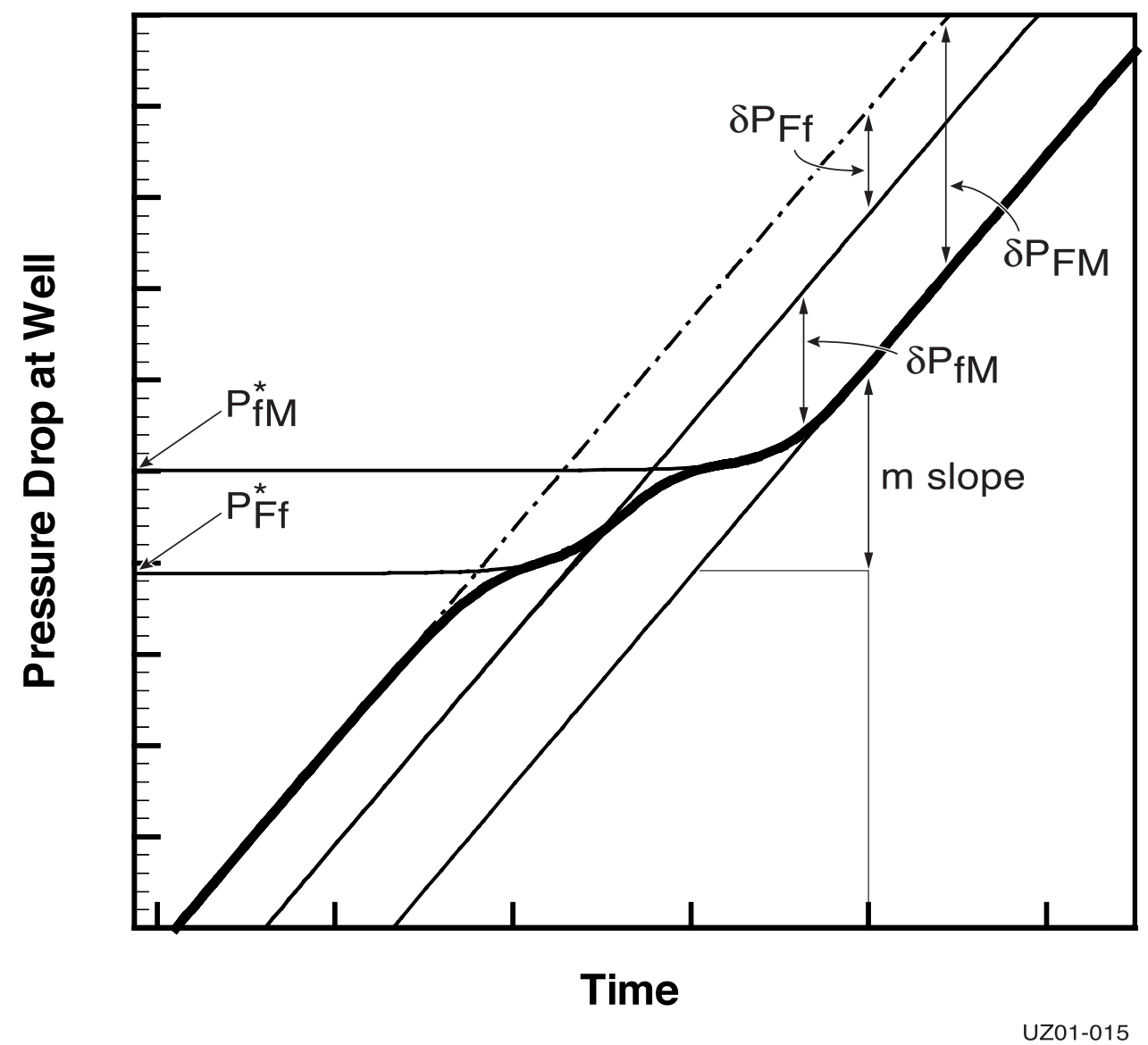

Figure 5. Schematic of pressure testing curves of flow through a triple-continuum fractured media, defining vertical distances and transitional point pressures for well-test analyses. 


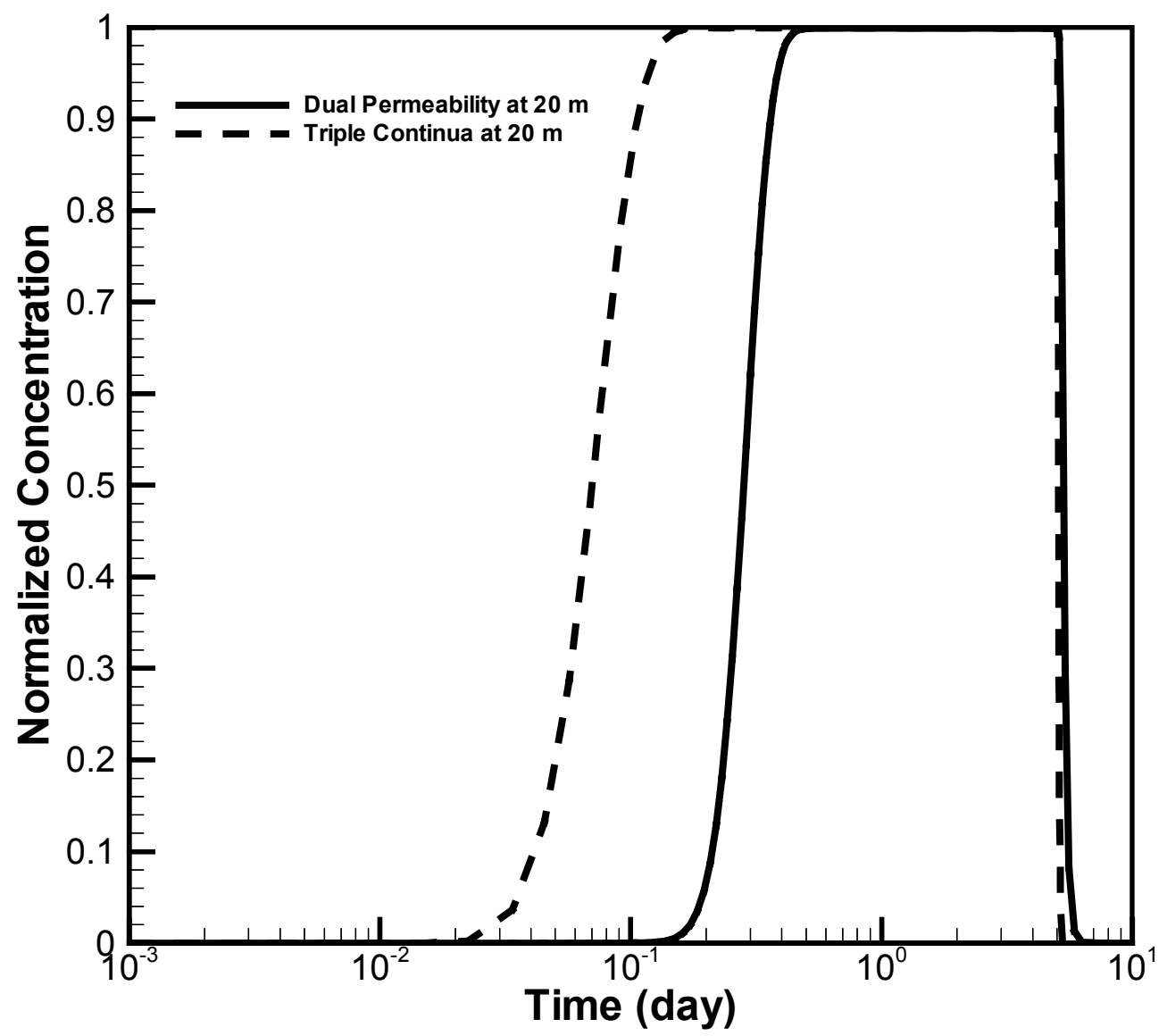

Figure 6. Breakthrough curves of relative tracer concentration at $20 \mathrm{~m}$ from the well for the scenario of dual-permeability model fracture porosity equal to combined porosity of large and small fractures in a triple-continuum model. 


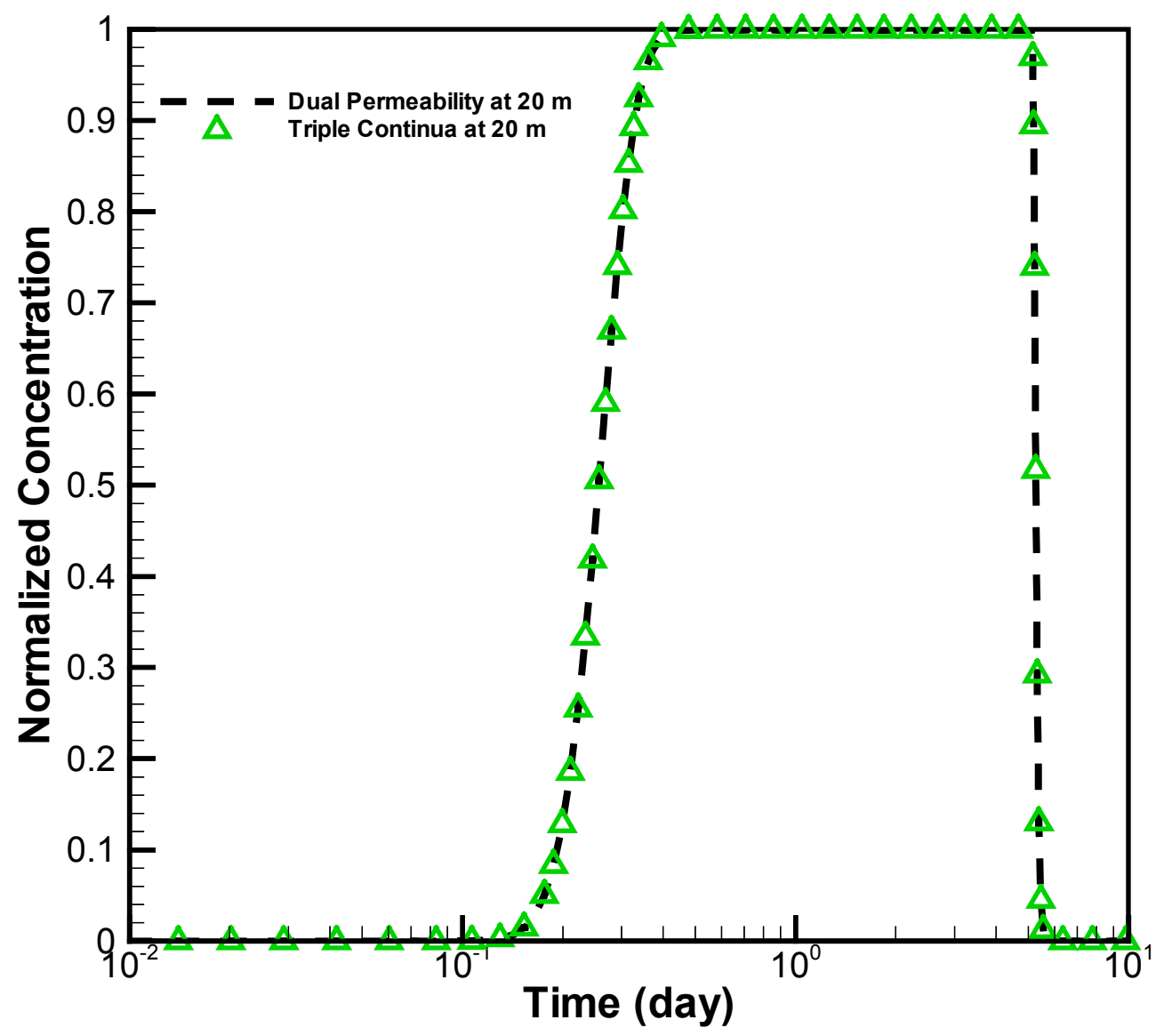

Figure 7. Breakthrough curves of relative tracer concentration at $20 \mathrm{~m}$ from the well for the scenario of dual-permeability model fracture porosity equal to large-fracture porosity with a triple-continuum model. 


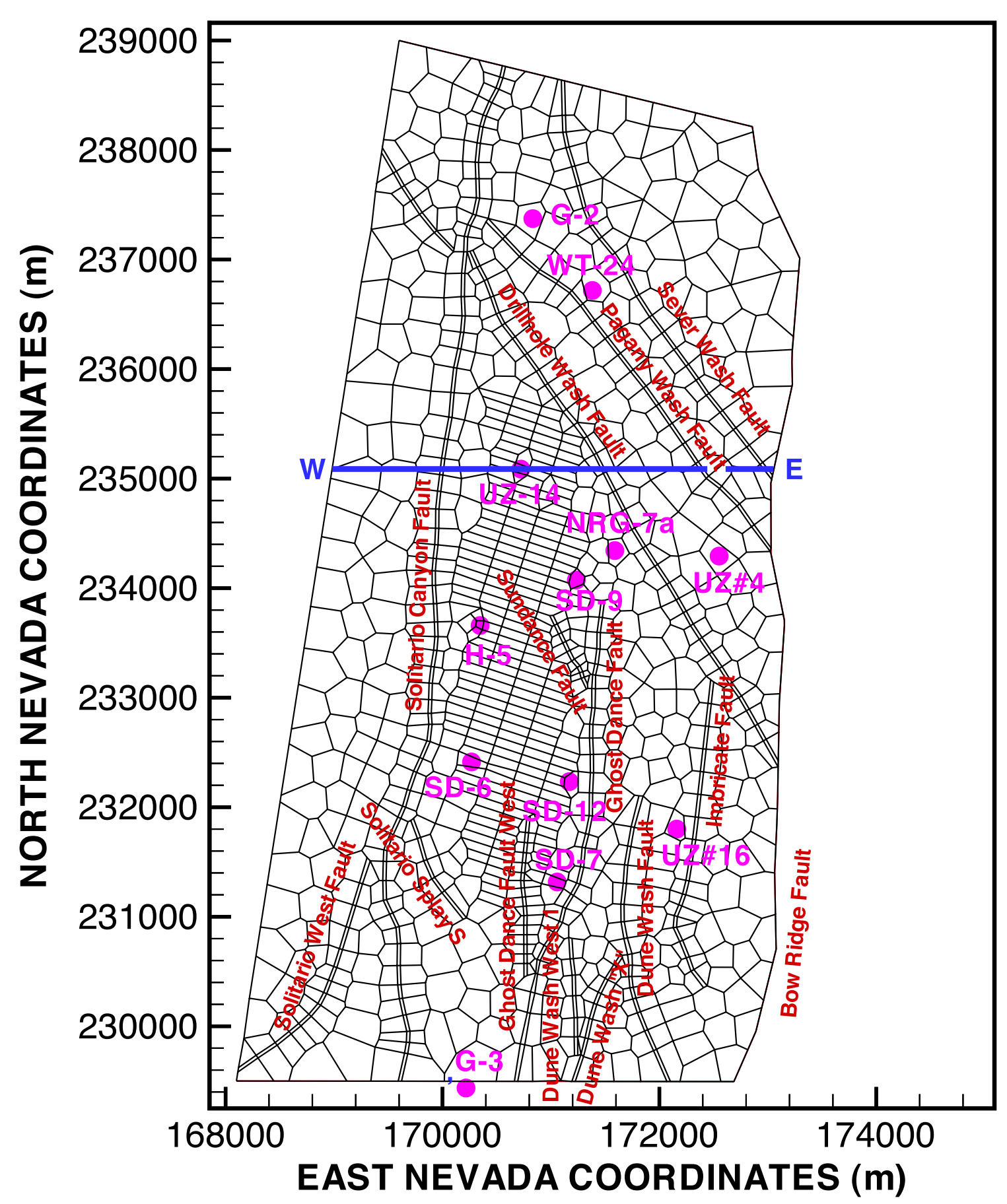

UZ01-016

Figure 8. Plan view of the 3-D UZ model grid, showing the model domain, faults incorporated and borehole locations at Yucca Mountain 


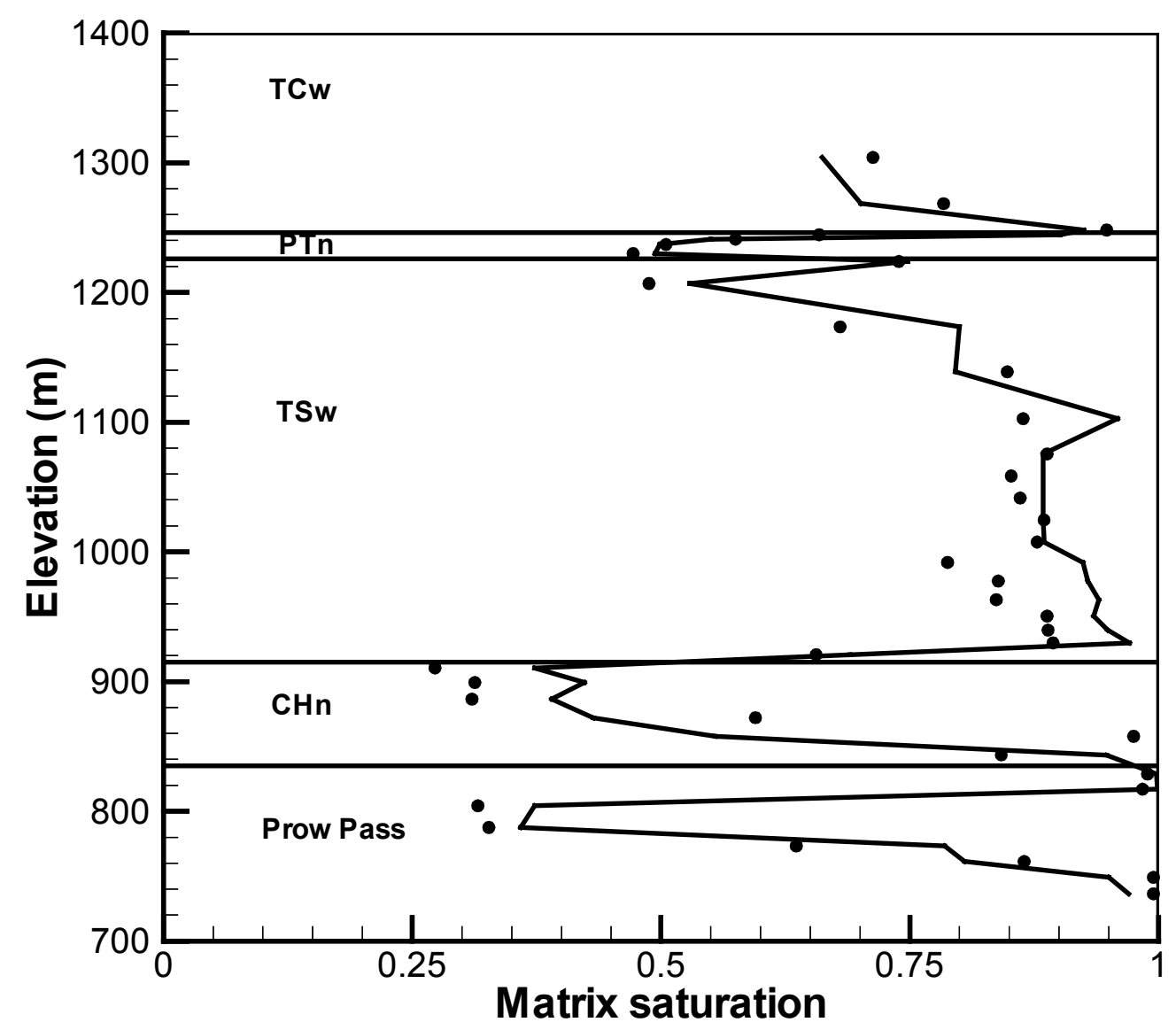

Figure 9. Comparison between the matrix water potential profile for the submodel corresponding to borehole SD-12 (solid line, obtained from inverse modeling) and the measured data (black circles). 
SD-7

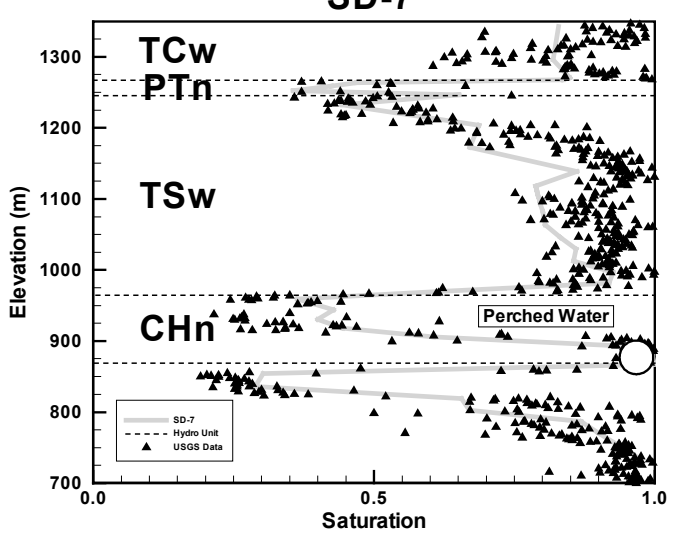

SD-12

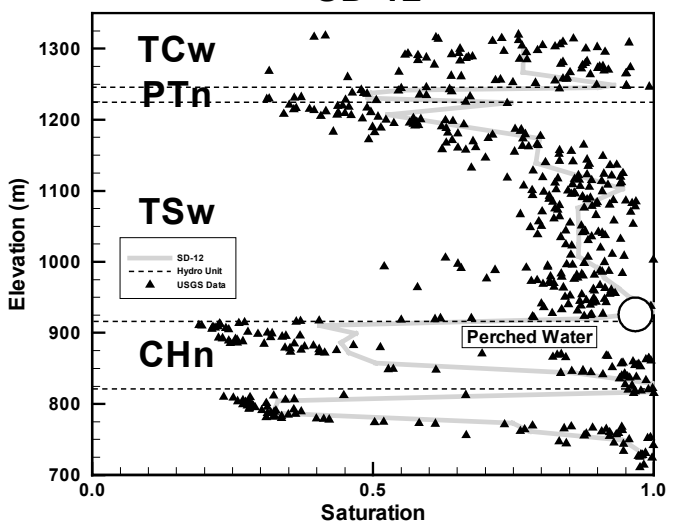

SD-9

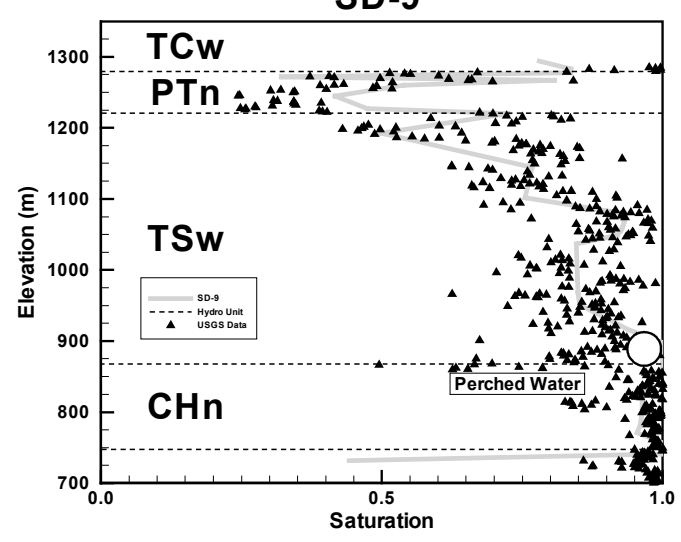

UZ-14

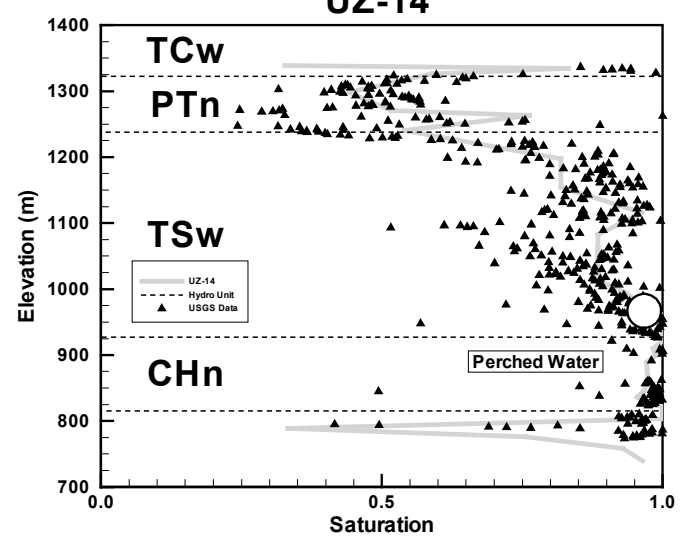

Figure 10. Comparison of the simulated and observed matrix liquid saturations and perched water elevations for boreholes SD-7, SD-9, SD-12, and UZ-14, using the triplecontinuum model-simulation results with present-day, mean infiltration rate (with the thin-dashed lines representing interfaces between hydrogeological units). 


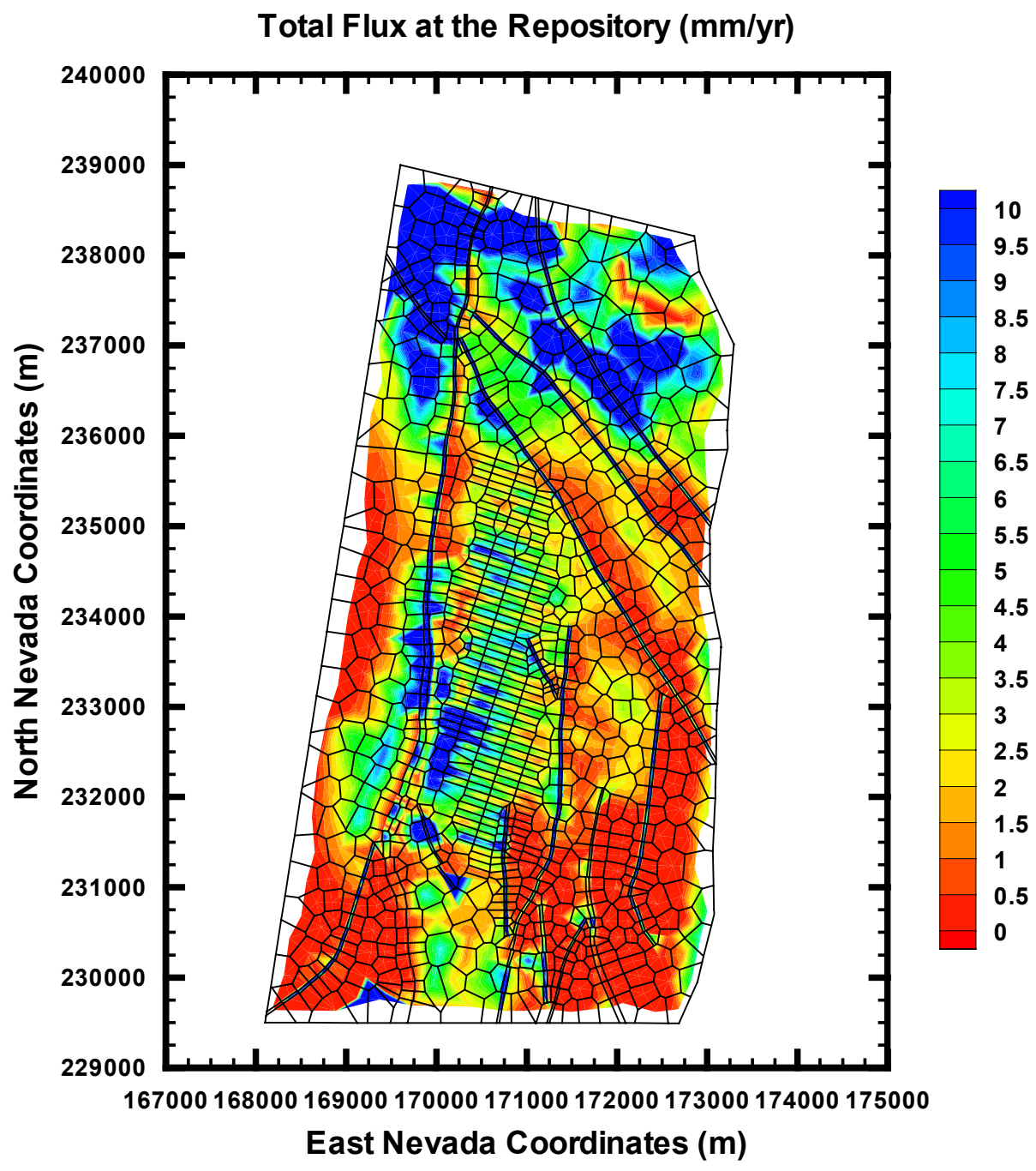

3k_pchm1

Figure 11. Simulated percolation fluxes at the repository level under the present-day, mean infiltration rate using the triple-continuum model. 


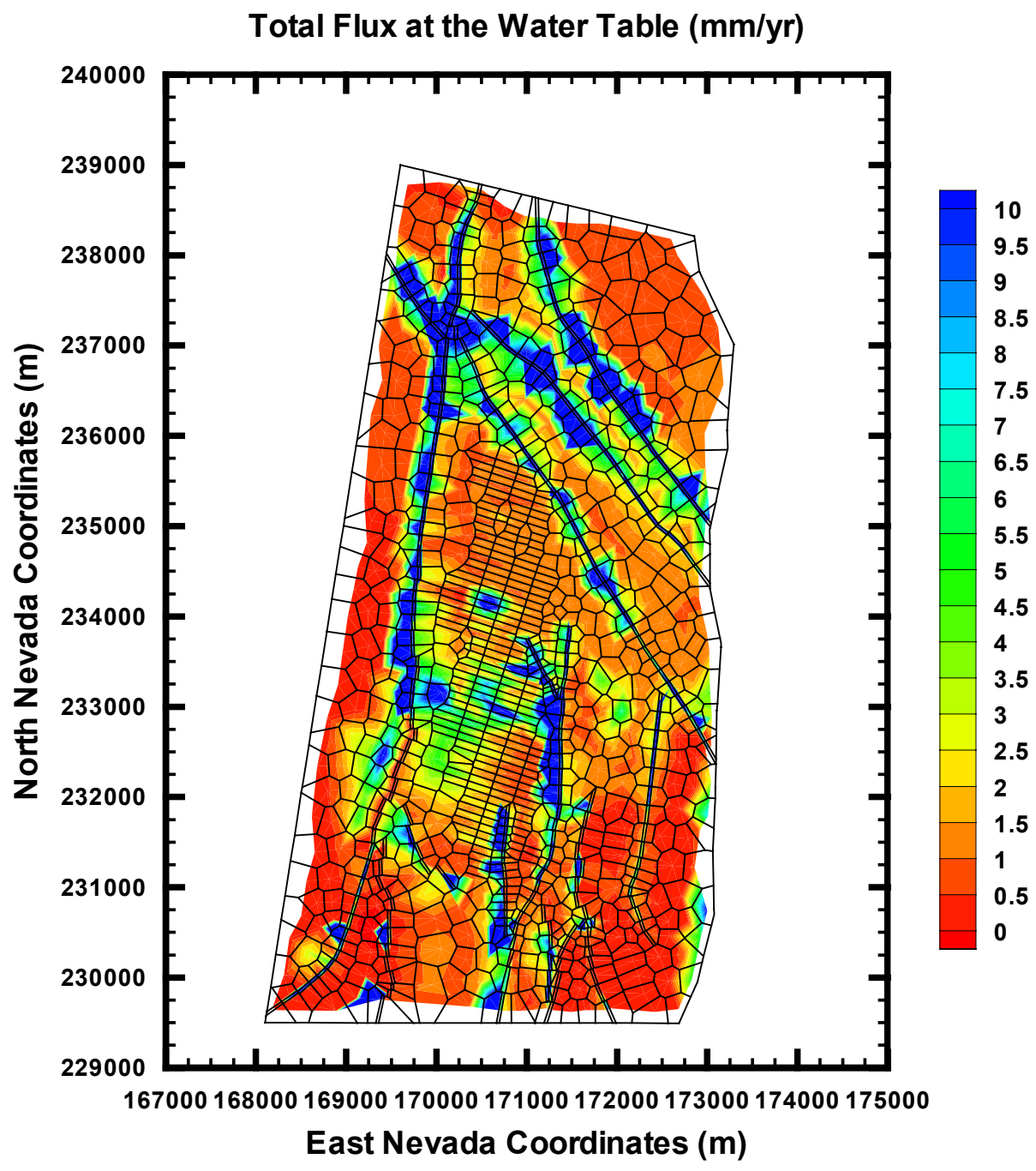

3k_pchm1

Figure 12. Simulated percolation fluxes at the water table under the present-day, mean infiltration rate using the triple-continuum model. 


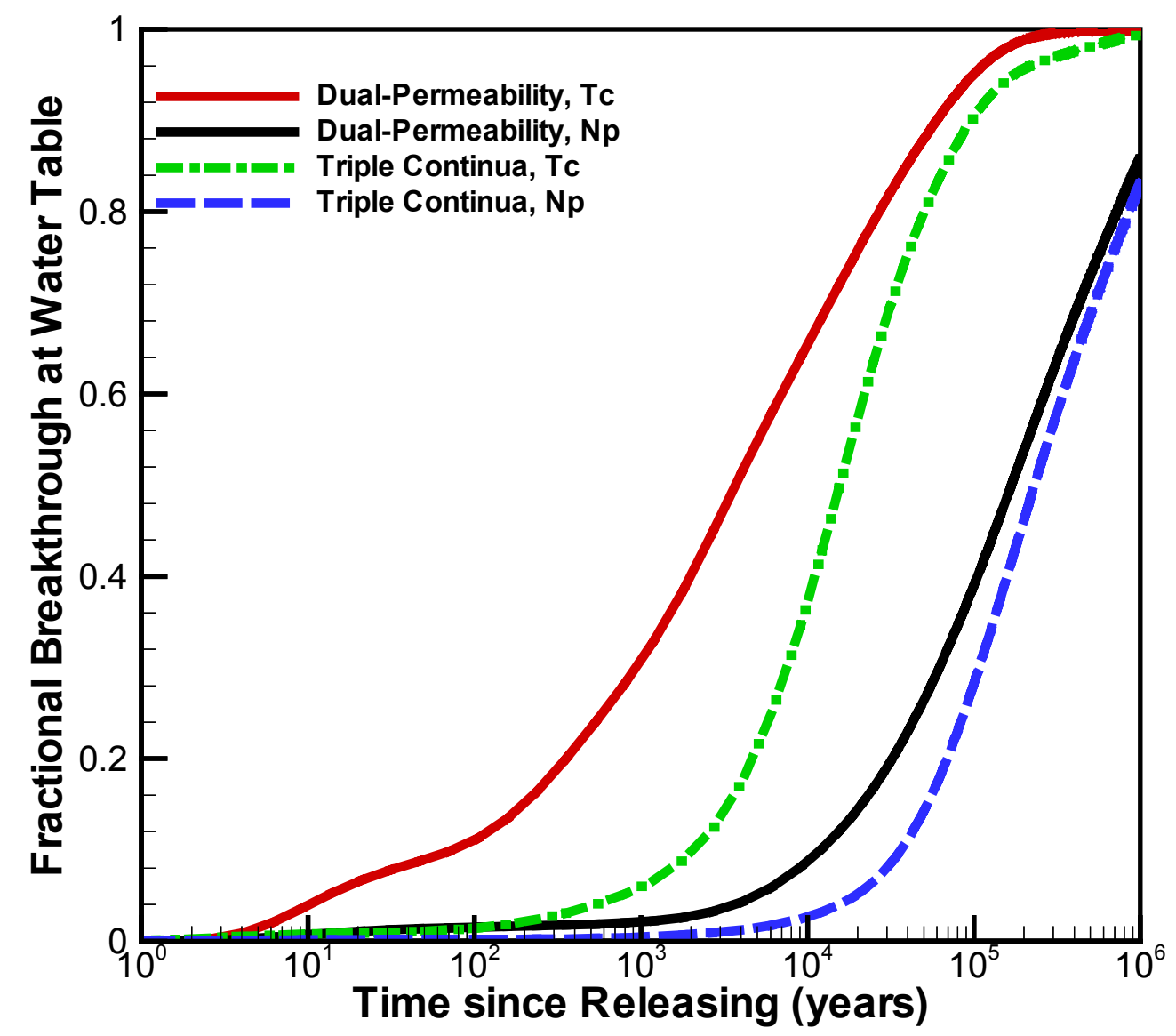

Figure 13. Comparison between cumulative breakthrough curves at the water table, simulated for conservative and reactive tracer transport from the repository with the dualpermeability and triple-continuum 3-D models, respectively. 


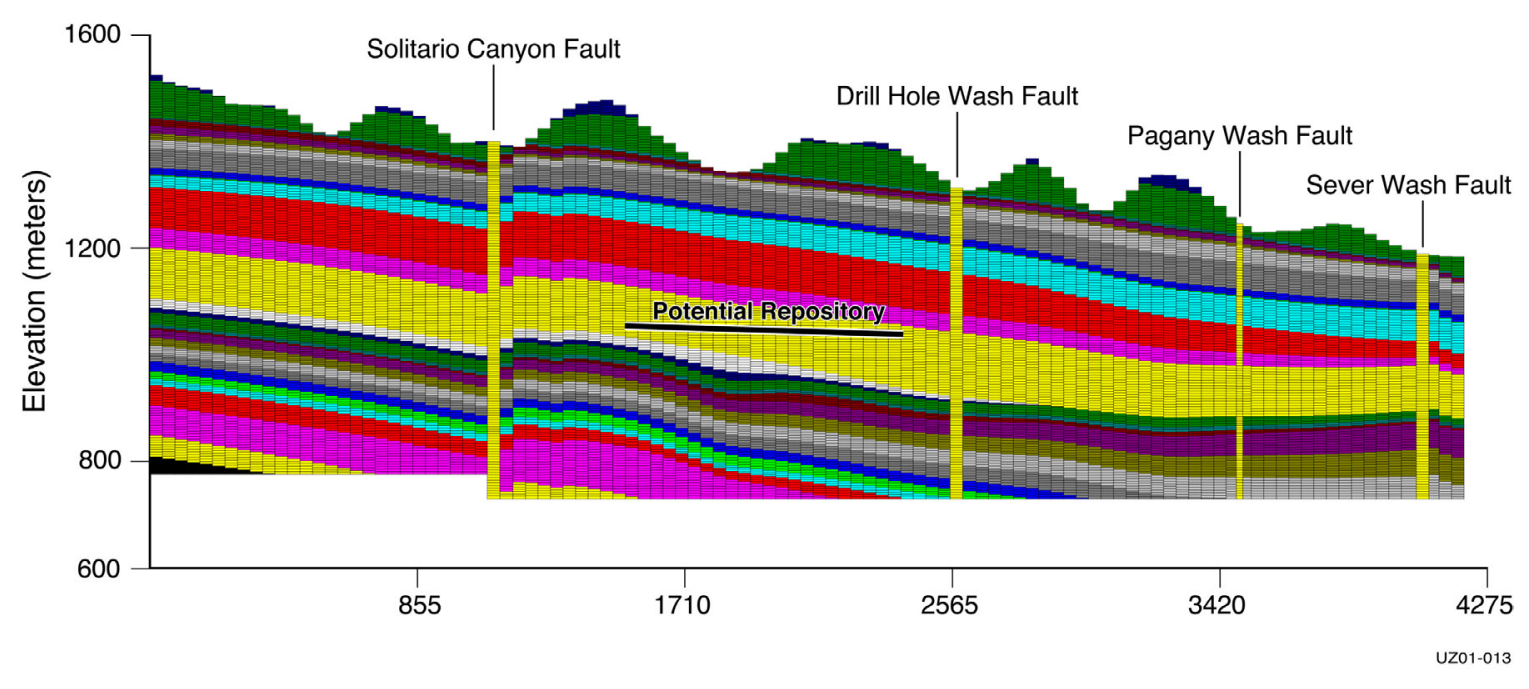

Figure 14. Two-dimensional grid showing geological layers, faults, and potential repository layout along the east-west cross section at UZ-14. 
(a)

UZ-14 Cross Section: Total Flux at the Repository

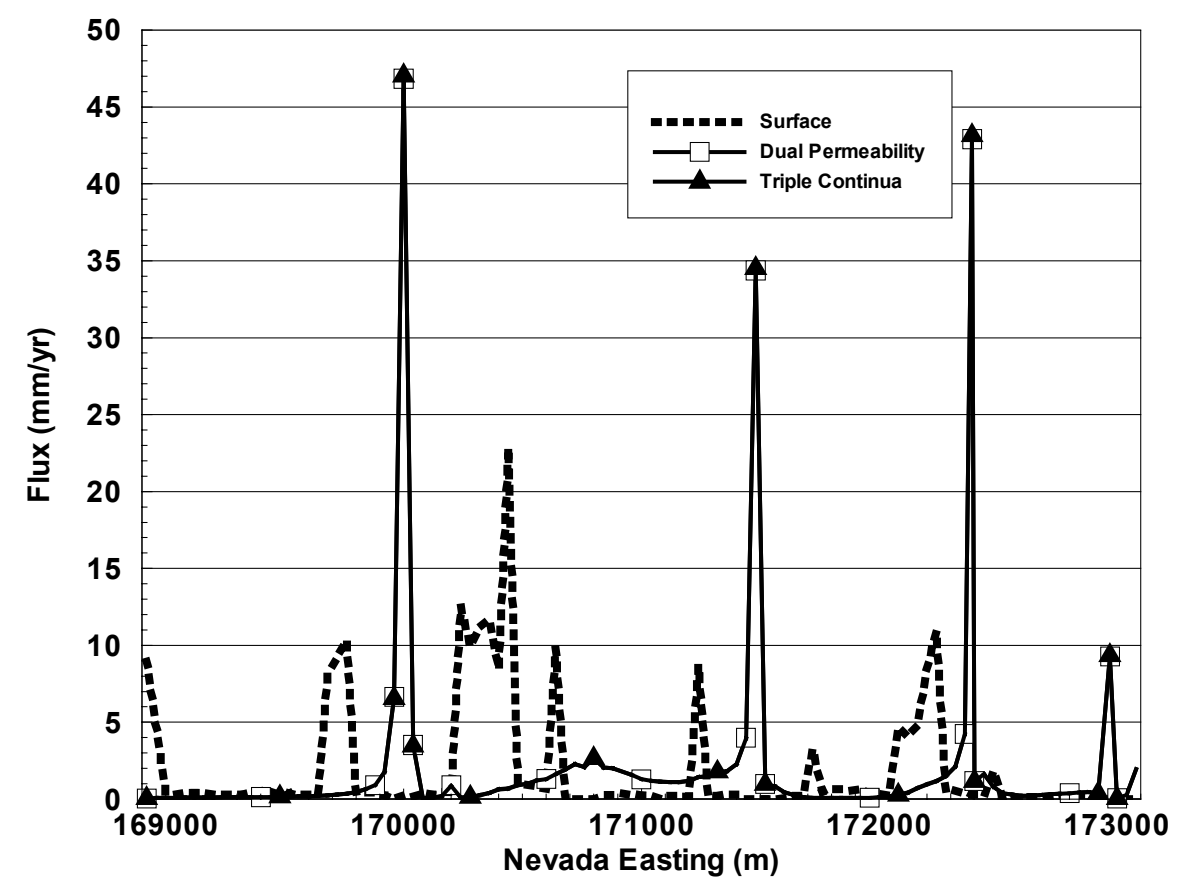

(b)

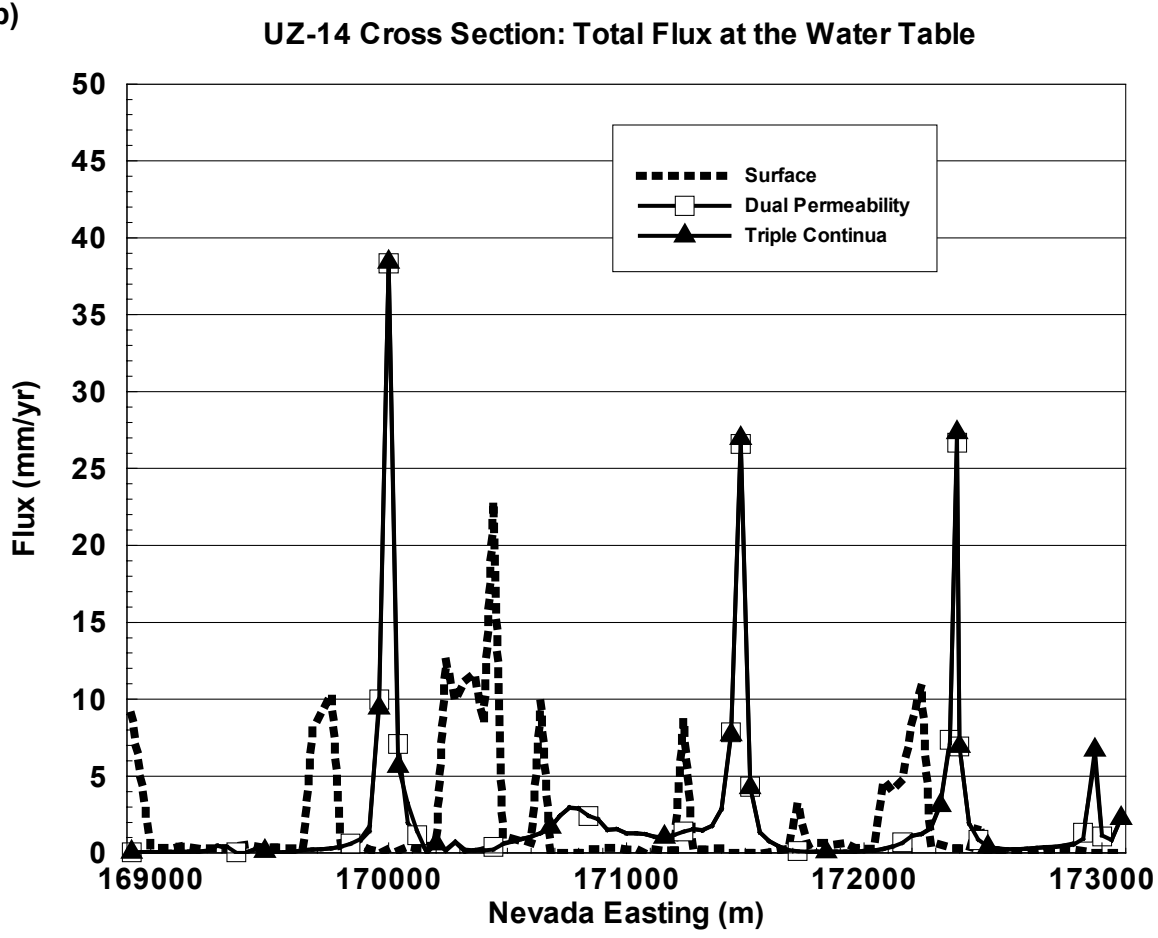

Figure 15. Comparison of surface infiltration rates and percolation fluxes (a) at the repository level and (b) at the water table, respectively, simulated using the dualpermeability and triple-continuum 3-D models. 


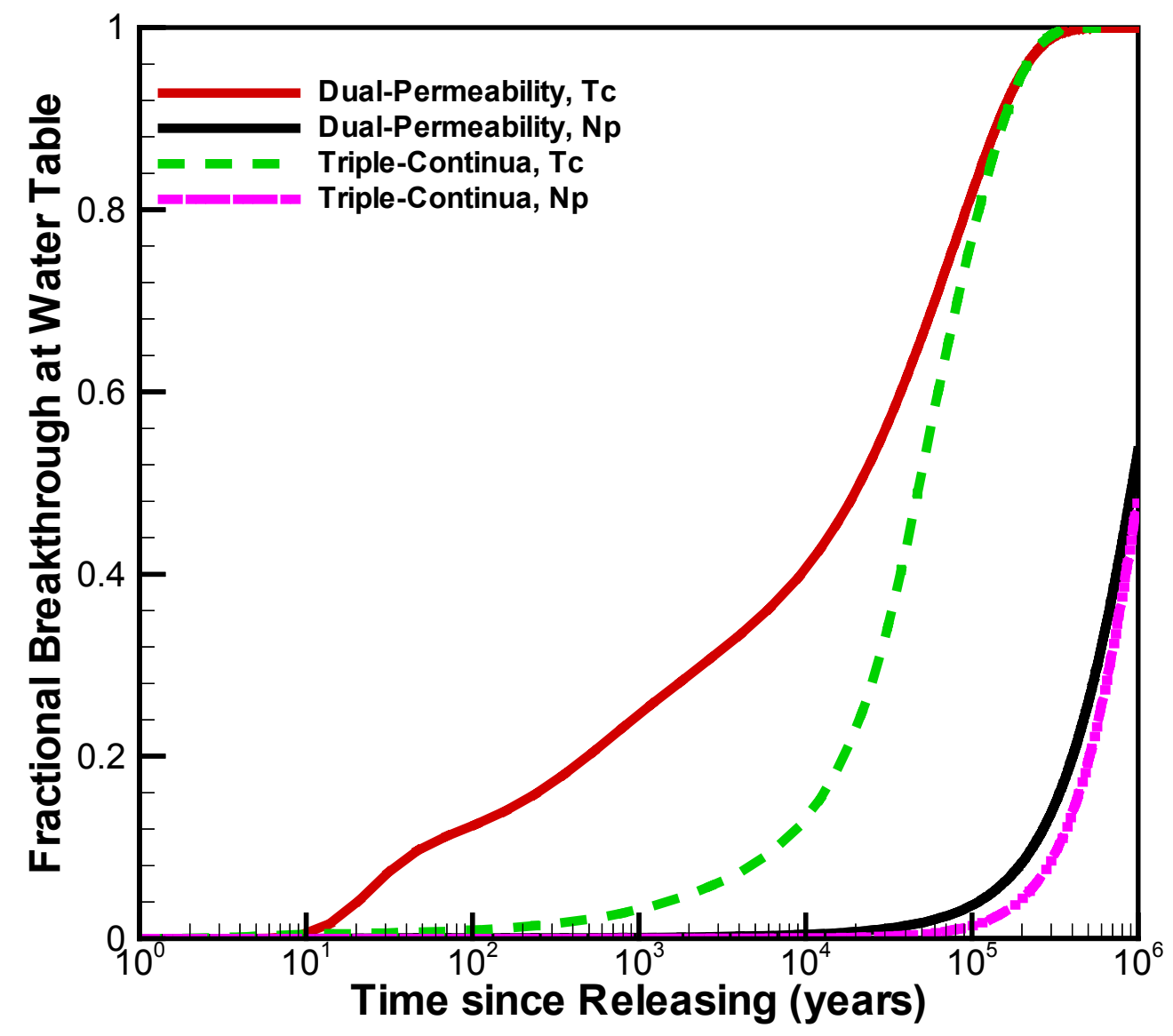

Figure 16. Comparison between cumulative breakthrough curves at the water table, simulated for conservative and reactive tracer transport from the repository, with the dualpermeability and triple-continuum 2-D models, respectively. 


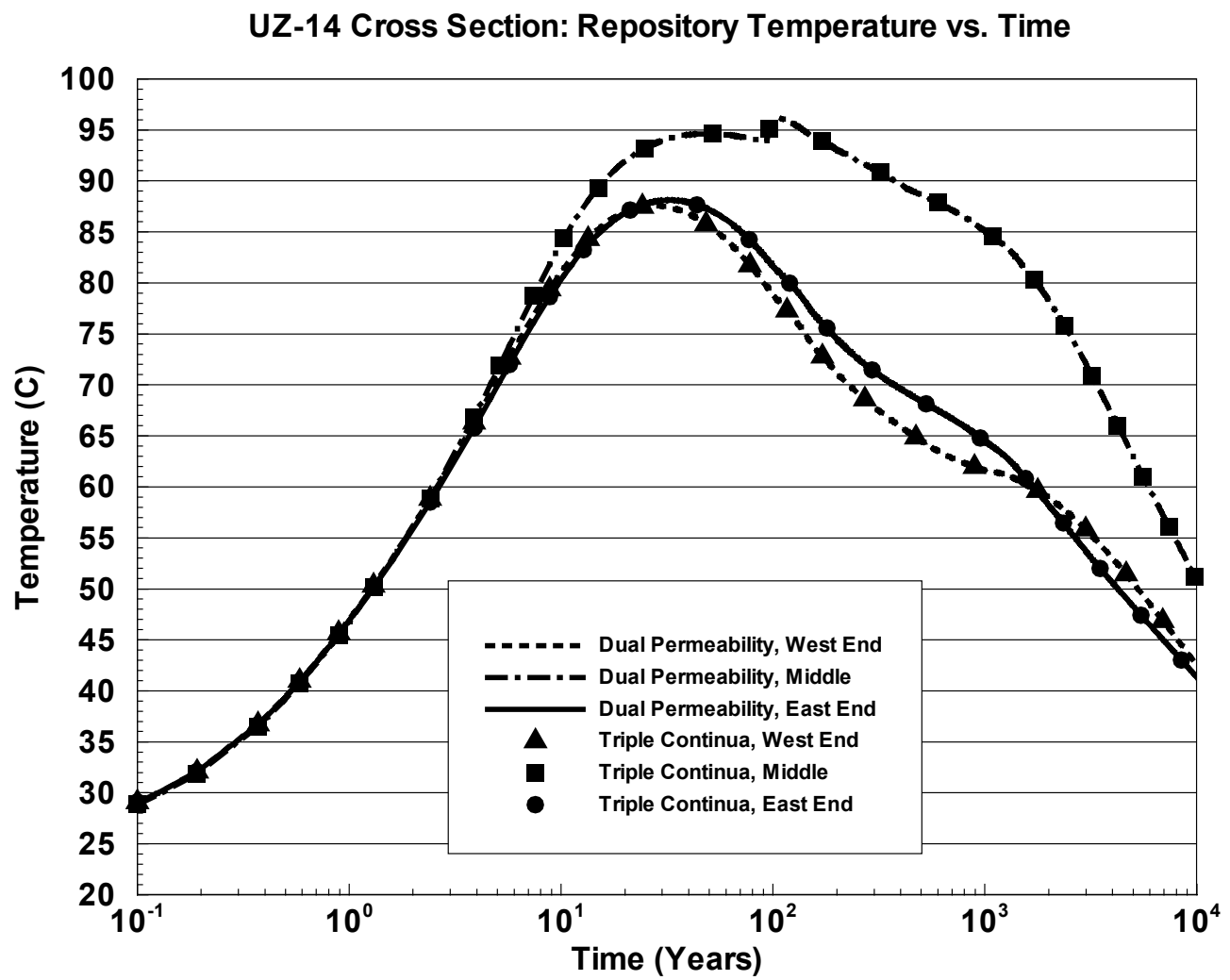

Figure 17. Comparison of repository temperature variations at three locations, simulated using the dual-permeability and triple-continuum 3-D models. 


\section{UZ-14 Cross Section: Mid-Repository Temperature}
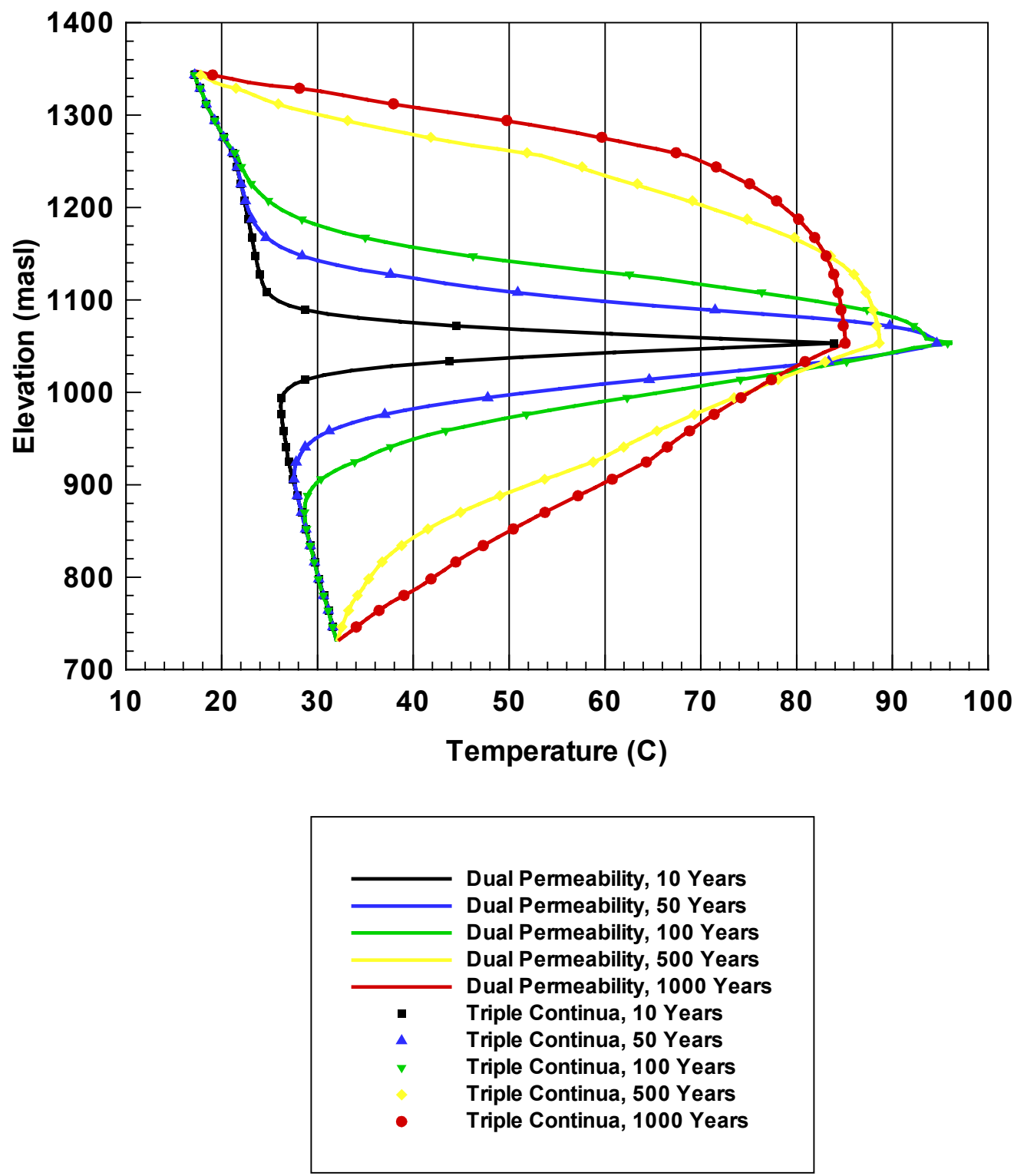

Figure 18. Comparison of vertical temperature profiles along the middle of the 2-D cross section at different times at three locations, simulated using the dual-permeability and triple-continuum 3-D models. 